Revue d'histoire de l'Amérique française

ZRS REVUE D.HISTOIRE DE L'AMÉRIQUE FRANÇAISE

\title{
Un gaumiste canadien : l'abbé Alexis Pelletier
}

\section{Thomas Charland}

Volume 1, numéro 2, septembre 1947

URI : https://id.erudit.org/iderudit/801367ar

DOI : https://doi.org/10.7202/801367ar

Aller au sommaire du numéro

Éditeur(s)

Institut d'histoire de l'Amérique française

ISSN

0035-2357 (imprimé)

1492-1383 (numérique)

Découvrir la revue

Citer cet article

Charland, T. (1947). Un gaumiste canadien : l'abbé Alexis Pelletier. Revue

d'histoire de l'Amérique française, 1(2), 195-236.

https://doi.org/10.7202/801367ar d'utilisation que vous pouvez consulter en ligne.

https://apropos.erudit.org/fr/usagers/politique-dutilisation/ 


\section{UN GAUMISTE CANADIEN : L'ABBÉ ALEXIS PELLETIER}

Au mois d'août 1861, débarquait à Québec un prêtre lorrain, l'abbé Jacques-Michel Stremler. Il venait enseigner la théologie à l'Université Laval, invité par le recteur, l'abbé Elzéar Taschereau, qui l'avait bien connu pendant son séjour de deux ans (1854-1856) à Ribme et qui aurait, à ce qu'on dit, eu recours à ses bons offices pour la préparation de ses examens de droit canonique. Car, en plus d'être un bon théologien, l'abbé Stremler était un excellent canoniste. Il avait été employé pendant trois ans à la Congrégation du Concile, avait été le collaborateur de Bouix, et venait tout juste de publier un Traité des peines ecclésiastiques, des appels et des Congrégations romaines (1861). Les prêtres du diocèse de Québec en vinrent à le regarder comme un oracle. Mgr Baillargeon aimait à prendre son avis dans les affaires difficiles. Quant aux autorités du Séminaire, elles ne tardèrent pas à se repentir de l'avoir invité, comme elles s'étaient repenties quelques années auparavant d'avoir accueilli un autre prêtre français, professeur d'histoire celui-là, l'abbé Brasseur de Bourbourg. Car l'abbé Stremler était gaumiste, c'est-à-dire partisan de la thèse de Mgr Gaume sur la réforme chrétienne des études classiques, et il eut le malheur d'y gagner des adhérents parmi les professeurs du Séminaire. Le plus ardent de ces néophytes était un tout jeune prêtre de grand talent, condamné à enseigner les mathématiques: l'abbé Alexis Pelletier ${ }^{1}$, dont les polémiques allaient retentir jusqu'a Rome.

$\mathrm{Au}$ cours des deux derniers mois de 1864, ils publièrent dans le Courrier du Canada, sous le titre de Christianisme et Paganisme, des

1. Alexis Pelletier était né le 26 avril 1837, à Saint-Arsène (alors partie de Cacouna), de Louis Pelletier et de Sophie Michaud. Il avait fait ses études classiques (1850-1859) et sa théologie (1859-1863) au Séminaire de Québec, et avait été ordonné prêtre par Mgr Baillargeon, le 19 septembre 1863. 
extraits d'un ouvrage de l'abbé Firmin Vervorst, Le Peuple de Dieu et le monde païen, puis,sous le titre Les Causes de la Révolution française, des extraits de la Révolution de Mgr Gaume. Un correspondant, qui signait $\mathrm{xxx}$, ayant félicité le journal d'avoir publié ces articles, Mgr Charles-Félix Cazeau, vicaire général du diocèse, adressa au rédacteur $\mathrm{du}$ Courrier le communiqué suivant: " $\mathrm{Au}$ sujet de certains articles qui ont paru dernièrement dans votre feuille concernant l'éducation des collèges, permettez-moi de vous inviter à publier l'extrait suivant de la lettre Encyclique du 21 mars 1853 par laquelle N. S. Père le Pape a mis fin à la dispute qui s'était élevée quelque temps auparavant sur cette question brûlante dans certains journaux catholiques de la France. Dans l'avant-dernier no. du Courrier un correspondant anonyme (quand on veut calomnier, on ne donne pas son nom) a porté contre nos collèges catholiques une accusation extrêmement grave et qui ne peut passer sans être relevée. Il affirme que les jeunes gens en " sortant des collèges ne savent rien de la Bible, des SS. PP. etc.; que l'on étudie les classiques pendant 8 à 10 ans et qu'on ne fait que lire superficiellement le catéchisme... ") ${ }^{2}$

$\mathrm{Au}$ printemps de l'année suivante, nos gaumistes se mirent à publier dans le même journal, sous la rubrique La Beauté de la vie des Saints, des esquisses hagiographiques, afin de prouver que les vies des saints valent autant pour le moins, du seul point de vue de l'intérêt, que les vies des prétendus grands hommes du paganisme. Vint le tour de la vierge martyre Fébronia, dont l'histoire dit qu'elle fut dépouillée de ses habits sur la place publique par des bourreaux qui voulaient user d'un raffinement de barbarie. Il n'en fallut pas davantage pour qu'Un Abonné (encore le G.-V. Cazeau, au dire de l'abbé Pelletier) protestât auprès du rédacteur du Courrier: « Si votre correspondant $\mathrm{X}$ tient à continuer d'encombrer votre feuille de ses articles, ayez donc la bonté de lui suggérer de mieux choisir les exemples dont il prétend nous édifier.

Il a une sainte horreur pour les auteurs païens, et je ne lui en fais pas un crime; mais je le blâme fortement de vouloir leur substituer des légendes, comme celle de F'ébronia, qu'il admire avec un enthousiasme beaucoup plus poétique que raisonnable. Pour moi je n'ai

2. Courrier du Canada, 23 déc. 1864. 
rien vu de plus déshabillé dans les auteurs que j'ai vus au collège.) ${ }^{3}$ Le Courrier se tint coi, cette fois encore.

Encouragé par son succès, et soucieux d'empêcher tout retour offensif de la part des gaumistes, le G.-V. Cazeau aurait alors battu le pavé et fait le tour des imprimeries de Québec pour enjoindre à leurs propriétaires de ne rien publier en faveur de la réforme chrétienne de l'enseignement, sous peine d'encourir sa disgrâce, celle du Séminaire et de l'Archevêché.

" On m'a enterré journaliste, je repousse brochurier », avait dit Louis Veuillot. Ainsi fit l'abbé Pelletier, son admirateur; avec cette différence, toutefois, qu'il prit la précaution, et pour cause, de se couvrir du voile de l'anonymat. Dès ce printemps de 1865 , il publia donc, l'une à la suite de l'autre, deux brochures anonymes. La première sortait de l'atelier typographique de Lussier et frère, propriétaires du Courrier de St-Hyacinthe, et avait pour titre: Mgr Gaume, sa thèse, et ses défenseurs. Il y exaltait la science de l'auteur du Manuel des Confesseurs, du Catéchisme de Persévérance, des Trois Rome, du Ver rongeur des Sociétés Modernes, et de la _évolution, en qui on avait voulu voir un exagéré. Puis il passait en rı rue les sources conciliaires et les approbations ecclésiastiques de la thèse gaumiste. Il prenait soin de dire en terminant son petit travail (p. 33): “ J'ose espérer... qu'on ne le regardera pas comme une attaque contre des individus en particulier ou contre nos institutions littéraires. )

La seconde brochure ne portait pas d'indication de lieu d'impression. Elle s'intitulait: Situation du Monde actuel, et était coiffée d'un sous-titre qui en précisait le contenu: Coup d' æil sur l'origine et la propagation du mal dans la société, ou développement des principales idées contenues dans le discours de Mgr Filippi, évếque d'Aquila, prononcé à l'Académie de la Religion Catholique à Rome, le 1er septembre 1864. On y lisait: " Ce discours a produit une sensation profonde, non seulement à Rome, mais dans toute la France... Il a aussi eu en

3. Ibid., 7 avril 1865. 
Canada un grand retentissement ${ }^{4}$; il a donné lieu à bien des réflexions et fait germer tout un monde d'idées nouvelles... Nous avons l'espoir que cette esquisse, par les détails qu'elle renferme, fera mieux sentir toute la force des raisons alléguées en faveur de la réforme chrétienne de l'enseignement. Ce qui nous a surtout déterminé à entreprendre et à exécuter ce travail, c'est l'importance toute particulière de cette réforme relativement à nous Canadiens français, issus d'une vieille et noble race, chrétienne et catholique avant tout. Pourrions-nous en effet nous condamner à rester oisifs et les bras croisés, à la vue de ce grand mouvement religieux qui se manifeste aujourd'hui en Europe, et des maux incalculables que l'élément païen, caressé par l'éducation depuis trois siècles, a fait souffrir à la société ? Le milieu dans lequel nous vivons; l'indifférence religieuse, l'hérésie, l'infidélité qui nous enveloppent de toutes parts, placées qu'elles sont sur toute la longueur de nos frontières, doivent nous mettre sur le qui-vive, et nous faire saluer avec amour et reconnaissance une réforme qui nous promet une existence durable, par là même qu'elle tend à développer et à fortifier l'esprit chrétien et religieux. Nous l'espérons donc, ce petit travail sera favorablement accueilli. Il n'est pas précisément notre œuvre; il n'est guère autre chose qu'une compilation de ce qu'ont écrit sur le mal actuel de la société, ses causes et ses remèdes, les écrivains du plus grand poids, dont nous reproduisons souvent textuellement de longs passages ") (pp. 4-5).

" De l'aveu de tous, les éléments constitutifs, les causes prochaines du mal actuel sont la Révolution française, le Voltairianisme, le Protestantisme, le Césarisme, le Rationalisme. Or, à moins de déchirer les unes après les autres toutes les pages de l'histoire moderne, il demeure bien établi que toutes ces causes ne sont que les effets successifs d'une cause première, le Paganisme réintroduit dans le monde chrétien par la Renaissance et perpétué par l'éducation 》(p. 41).

"Quelle monstruosité, pour ne pas dire quel sacrilège, qu'une éducation qui se donne presque exclusivement au moyen de livres païens, où Satan tient la place de Dieu, où l'erreur est affirmée et la vérité tenue captive quand elle n'est pas niée, où le vice est chanté,

4. Il fut publié dans le Courrier du Canada des 6, 8 et 20 février 1865. (Note de l'auteur). 
loué, préconisé et la vertu rendue vile et méprisable. Oui, nous en sommes rendus là! des païens pour instruire les chrétiens! des damnés pour former des Saints! l'ange des ténèbres pour nous faire saluer les splendeurs du jour qui ne s'éteindra pas! Voilà le crime dont l'éducation actuelle est coupable ") (p. 93).

( Tout en rendant pleine justice au zèle et à la vertu de nos maîtres, nous ne pouvons ici nous empêcher de protester avec énergie contre le système d'enseignement païen qui forma notre enfance, et de déplorer l'ignorance en matière de religion qui en fut la conséquence obligée. Au sortir du collège nous savions par cœur les noms, l'histoire, les attributs, les aventures des dieux et des déesses de la fable; nous connaissions les Danaïdes et les Parques, Ixion et sa roue, Tantale et son supplice, les oies du Capitole et les poulets de Claudius. Sans broncher, nous aurions pu faire la biographie de Minos, d'Eaque et de Rhadamante, de Codrus et de Tarquin, d'Epaminondas, de Scipion et d'Annibal, de Cicéron et de Démosthène, sans excepter celle d'Alexandre et de César, d'Ovide, de Salluste, de Virgile et d'Homère. Lycurgue, Socrate, Platon, les Flamines, les Jeux du Cirque et de l'amphithếtre, les sacrifices, les fêtes, les comices du peuple-roi nous étaient connus. En un mot, nous possédions tout le savoir désirable dans d'honnêtes jeunes gens de Rome et d'Athènes, rejetons des Brutus ou des Gracques, candidats des gloires du forum, adorateurs ou prêtres futurs de Jupiter et de Saturne.)

( Mais si par malheur on nous eut transportés sur le terrain du christianisme et qu'on nous eut demandé des détails sur la hiérarchie et les divers chœurs des anges, sur la constitution de l'Église, sur le nombre et les noms des principaux conciles; si on nous eut priés de dire les noms des douze apôtres, le nombre de leurs épîtres; si on nous eut interrogés sur nos saints et nos martyrs, sur nos héros et nos gloires, les Chrysostome, les Augustin, les Athanase, les Ambroise, les rois de l'éloquence et de la philosophie chrétienne, les pères du monde moderne, nos maîtres dans la science de la vie; si on nous eut demandé à nous, leurs enfants, les enfants de l'Église et des martyrs, quelle fut l'époque de leur naissance, quels combats ils eurent à soutenir, quels ouvrages ils composèrent, quelles actions leur méritèrent l'admiration des siècles et le culte de l'univers, on nous eut parlé une langue inconnue. La rougeur de notre front et l'humiliante immobilité 
de nos lèvres, en excitant la pitié de l'homme sensé, eussent mis à nu le contresens monstrueux de nos études classiques. Telle est notre histoire, et peut-être celle de bien d'autres ") (pp. 77-78).

" ...il n'y a de salut pour la société, comme pour les individus, que dans une éducation qui enseignera tout au point de vue chrétien (p. 94). Pour nous, nous demandons, comme Mgr Gaume, que les auteurs chrétiens soient les classiques exclusifs des enfants jusqu'à la quatrième inclusivement; qu'après la quatrième, ils continuent à être étudiés simultanément avec les auteurs païens, parfaïtement expurgés, et qu'alors encore ils tiennent la place d'honneur qui leur est due. ") (pp. 95-96).

Inutile de dire que ces deux brochures déplurent beaucoup à certains prêtres du Séminaire de Québec. L'un d'eux, l'abbé Thomas Chandonnet, professeur de philosophie, se chargea de les réfuter. Il publia dans le Journal de Québec une série d'articles ${ }^{5}$, où il rectifiait des citations des auteurs profanes, des Saints Pères, des conciles et des encycliques. L'abbé Pelletier lui répondit dans une troisième brochure, La Question des classiques en présence des rectifications et des critiques de M. l'abbé Chandonnet, qu'il signa Un "Chrétien ». Il commençait par disposer du reproche que l'abbé Chandonnet avait fait aux gaumistes de ne pas avoir signé leurs articles et leurs brochures et d'y avoir fait briller, en guise des leurs, les plus beaux noms de l'histoire: « M. l'abbé est loin d'ignorer pour quelle raison les écrivains dont il parle tiennent à ne pas être connus. Il sait qu'on a organisé contre eux une véritable persécution; qu'on a remué ciel et terre pour empêcher les journaux de publier leurs écrits, et que même certaine feuille perdrait son existence, si elle osait encore reproduire une ligne en faveur de la méthode chrétienne. Voilà ce que M. l'abbé ne doit pas ignorer, d'autant plus que lui-même, nous dit-on, a joué un rôle dans toutes ces manœuvres... Quant à nous, si nous étions des personnages de la stature de M. l'abbé, et que, d'un autre côté, les inconvénients que nous venons de signaler n'existassent point, nous ferions comme lui, nous mettrions toujours notre nom en relief. Un homme dont le

5. Sous le titre Défions-nous des citations (Journal de Québec, 6 et 13 juin et 4 juillet 1865). Il interrompit sa série quand il s'aperçut qu'un de ses confrères du Séminaire, l'abbé Félix Buteau, commençait à publier dans la même feuille $(3,6$, 7 et 8 juillet) ses Observations sur les rectifications de M. T.-A. Chandonnet. 
nom porte un cachet d'autorité peut se permettre bien des choses que ne saurait tenter le commun des mortels ") (pp. 3-4).

Devenant un peu plus narquois, il écrivait: " Nous nous hâterons de le dire, M. l'abbé Chandonnet n'a pas l'impétuosité cassante et mal apprise d'un de ses alliés, le Conservateur ${ }^{6}$. Tout au contraire, il est grave et même solennel; il ne marche jamais que remparé de: textes authentiques. Dans ce majestueux appareil, il cherche bien le mot pour rire, faisant son possible pour égayer par un peu de raillerie son aride matière; mais rien ne dépasse la limite: une gaieté de professeur, une épigramme de philosophe, et puis toute une suite de textes authentiques, et jamais de gros mots. C'est pourquoi nous lui répondrons avec la plus grande bienveillance possible ") (p. 5). Il tint parole jusqu'à la fin... exclusivement. "Toutefois, nous le savons, disait-il en terminant, tant de preuves accumulées ne produiront pas un grand effet sur l'esprit rétif de M. l'abbé, non plus que sur celui d'un certain nombre d'autres à parti pris, comme lui. Ils veulent. avoir raison envers et contre tous, et fallût-ı. pour cela organiser de nouvelles persécutions, ils ne reculeront pas; ils inrifieront talents et vertus ) (p. 43).

Ce qu'il avait prévu arriva. L'abbé Désiré Vézina, un ami de M. Stremler, fut chassé du Séminaire. Il avait dit à ses élèves que les. grands hommes du paganisme n'étaient que des pygmées en présence des grands hommes du christianisme, les saints, ajoutant que la véritable grandeur s'apprécie d'après la ressemblance plus ou moins parfaite avec Jésus-Christ, le type et le modèle des vrais grands hommes, qu'en conséquence on ne pouvait guère espérer de trouver cette grandeur dans le paganisme, qui n'avait été que le règne des trois concupiscences. On lui reprochait d'avoir attaqué par ces paroles le système d'enseignement du Séminaire, puis d'avoir tenu un langage indécent devant ses élèves en nommant les trois concupiscences ${ }^{7}$. Deux mois après, l'abbé Stremler lui-même était remercié de ses services et partait pour le diocèse de Cleveland.

6. Ce Conservateur avait publié dans le Canadien du 17 mai 1865, un article pour défendre nos collèges classiques. Voulant se montrer impartial, le même journal avait accueilli, le 22 mai, un article gaumiste intitulé Du Paganisme dans l'Enseignement et signé XXX. (Note de l'auteur).

7. La Source du Mal de l'Epoque, par un catholique, 31-32. 
Quant à l'abbé Pelletier, il démissionnait, l'année suivante (21 mai 1866), comme prêtre auxiliaire du Séminaire de Québec et prenait le chemin du Collège de Sainte-Anne de la Pocatière, emportant, on le pense bien, tout son bagage d'idées réformistes. Il y installa ses batteries et continua de bombarder la forteresse québécoise. De 1866 a 1868, il publia trois nouvelles brochures sous le pseudonyme de George St-Aimé. Sauf un petit nombre d'amis dévoués et très discrets, personne ne savait qu'il en était l'auteur.

Il fit imprimer par G.-E. Desbarats, à Ottawa, la première de cette série: La Méthode chrétienne considérée dans ses avantages et sa nécessité et réponses à certaines difficultés. En voici quelques extraits: "Nous venons aujourd'hui prêcher derechef la croisade contre le paganisme dans l'éducation, espérant, malgré toutes les qualités qui nous manquent pour accomplir dignement le rôle que nous assumons, apporter de nouveaux développements à ceux qui ont déjà été donnés. Certains articles de journaux, certains discours, tout imprégnés de paganisme et livrés à la publicité depuis les dernières luttes, prouvent surabondamment que notre démarche est légitime et nécessaire (p. 3). Sans doute il est pénible de contrister le cœur de ses frères; mais, à notre avis, il l'est encore plus de sacrifier les droits de la vérité. La première charité du chrétien, c'est l'amour de la vérité (p. 5). Le scandale qui résulte de nos discussions sur un pareil sujet, si scandale il y a, est un mal bien léger, qui ne saurait nullement faire contrepoids aux avantages qu'elles nous promettent » (p. 7).

Il assimile à la conduite des pharisiens " le rôle qu'ont joué, l'an dernier, certains personnages qui, nous dit-on, couraient d'un bureau de journal à un autre, afin d'arrêter la publication d'écrits destinés à mettre la méthode chrétienne en honneur (p. 14). Quelques nourrissons de Rome et d'Athènes allaient infailliblement déclarer banqueroute intellectuelle, si l'on substituait l'idée chrétienne à l'idée paienne. Qu'allaient devenir leurs trésors de lieux communs et de remarques? Toutes ces richesses n'auraient plus eu de cours. Il aurait fallu les refondre et leur donner une nouvelle forme et une nouvelle empreinte; le génie seul pouvait le faire, et ils ne l'avaient pas. Le moindre homme de bon sens leur aurait été comparable et même leur serait passé sur le ventre, malgré tout le grec et le latin dont ils étaient hérissés. Comme ils ne pouvaient décemment crier famine, malgré leur humilité (car eux-mêmes se sont proclamés, par l'organe d'un 
élégant et d'un lettré de la bande, hommes très modestes, dans un flamboyant article sur l'Université Laval), ils imaginèrent de mettre en cause avec eux l'Eglise et l'autorité (p. 14). Pour voir une injure faite à l'Eglise dans l'attitude que prennent les défenseurs de la méthode chrétienne, il faut être ou profondément aveuglé ou sous l'influence d'une morsure encéphalique qui rend inévitablement christianophobe 》 (p. 10).

Après avoir repris les mêmes arguments et ressassé les mêmes témoignages en faveur des classiques chrétiens, il en vient à démontrer - et c'est en cela que consistent les nouveaux développements qu'il a promis - que « le seul latin qu'on puisse apprendre, qu' on puisse parler correctement et convenablement, eu égard aux changements qu'a subis l'ordre social depuis le siècle d'Auguste, est le latin chrétien, c'est-à-dire le latin de la Bible, de l'Evangile, des Pères et des Docteurs de l'Eglise. Ce latin diffère essentiellement du latin païen; mais en son genre il est du bon, du beau, du très beau latin... les pensées qu'il revêt ne sont pas, comme celles qu'habille le latin païen, creuses, niaises, vides de choses et de sens, dangereuses et funestes, mais tout à fait propres à nourrir le cœur et à fortifier l'intelligence (p. 38). Et pourtant on condamne la jeunesse à user les plus belles années de sa vie sur des fables et des sornettes, on expose même ses mœurs et sa foi pour apprendre ce beau latin qu'elle ne saura jamais, quelles que soient son application et son aptitude, aussi bien que le dernier cuisinier des Romains ! Et nous parlons de la force des études, et nous entendons certains professeurs vanter quelques-uns de leurs élèves en disant qu'ils connaissent toutes les grâces et toutes les finesses de la langue du siècle d'or! Quel enfantillage! Quelle pitié!» (p. 25)

Cette brochure de l'abbé Pelletier est la meilleure de toutes celles qu'il a publiées jusqu'ici ou qu'il publiera à l'avenir sur la question des classiques ${ }^{8}$. La démonstration qu'elle présente est très forte, il faut l'avouer. L'accepter, c'eût été, pour le Séminaire, " déclarer banqueroute intellectuelle ". L'intervention de l'autorité dio-

8. L'abbé Antonin Nantel en fit une critique ironique dans la Revue Canadienne de septembre 1866 (vol. III, 570-571). George Saint-Aimé rédigea une longue Réponse aux attaques de M. Nantel dirigées contre la Méthode chrétienne; mais on lui conseilla de ne pas la publier pour éviter de se faire des ennemis au Séminaire de Ste-Thérèse. 
césaine s'imposait, cette fois; et elle ne manqua pas de se produire. Ce fut sous la forme d'une consultation de Rome.

Le 23 novembre 1866, Mgr Baillargeon envoyait à la Sacrée Congrégation de l'Inquisition (Saint-Office), avec le programme d'études du Séminaire et la brochure La Méthode chrétienne de George St-Aimé, une lettre où il demandait: "Si l'usage presque exclusif des auteurs paiens, tel qu'il se pratique dans les Institutions de Rome, dans la plupart des Séminaires et des Collèges du monde catholique, et en particulier dans notre Séminaire diocésain,... n'est que toléré par l'Église, et si elle ne le souffre qu'à cause de la grande difficulté de le faire disparaître; si, dans les Conciles de Latran et de Trente, dans l'Encyclique Inter multiplices, et autres documents authentiques, l'Eglise a voulu que les écrits des Saints Pères eussent la plus large part dans les études classiques, et si, en particulier, l'on doit entendre la seconde partie de la septième règle de l'Index en ce sens qu'elle défende aux enfants la lecture des auteurs païens, quels qu'ils soient; si l'étude des classiques païens, telle que pratiquée dans nos collèges, est de nature à inculquer le paganisme dans l'esprit des jeunes gens, à mettre en danger leur foi et leurs mœurs, à en faire des sceptiques et des incrédules, et si enfin cette étude est bien réellement une des causes de tous les maux qui menacent aujourd'hui la société, comme on a voulu le prétendre, de sorte qu'un des moyens de salut pour la société chrétienne serait de cesser d'enseigner les auteurs païens, au moins dans les basses classes. )

La réponse de Rome fut prudemment calculée, comme toujours. Le cardinal Patrizi répondit à Mgr Baillargeon: " D'après la lettre que vous m'écriviez l'an dernier, en date du 23 novembre, les Eminentissimes Cardinaux qui sont en même temps que moi préposés à la Sainte Inquisition, ont appris avec une grande douleur que dans votre diocèse, de graves dissentions s'étaient élevées, surtout parmi les ecclésiastiques, et qu'elles y produisaient encore aujourd'hui de l'agitation, parce que dans l'enseignement des lettres humaines, tant dans votre Séminaire diocésain que dans les autres Collèges où étudient les enfants et les jeunes gens, et qui sont soumis à votre surveillance et à votre autorité, on explique les auteurs païens, tout expurgés qu'ils soient. Il n'y a certainement pas lieu, pour ces ecclésiastiques, de penser qu'il faille mettre ces livres de côté dans l'enseignement littéraire, ni de se montrer à cet égard si inquiets et si grandement 
alarmés. La chose a été examinée et elle a reçu la sanction que donne un usage antique et constant: les jeunes clercs peuvent sans aucun péril apprendre très bien l'art de parler et d'écrire élégamment et avec éloquence, tant dans les œuvres éminemment sages des Saints Pères que dans les auteurs paiens les plus célèbres, purifiées de toute souillure. Cela est non seulement toléré par l'Eglise, mais entièrement permis, comme Notre Saint Père le Pape Pie IX l'a clairemènt déclaré dans sa lettre encyclique adressée aux évêques de France, en date du 21 mars 1853. Puis donc que les livres païens, soit grecs, soit latins, dont on fait usage dans le séminaire et les collèges mentionnés plus haut, ne sont pas de ceux qui traitent de choses lascives ou obscènes, qui les racontent ou les enseignent, et qu'en outre ils ont déjà été purifiés de toute souillure avec le plus grand soin possible, comme vous m'en donnez vous-même la haute garantie, il n'y a certainement rien qu'on puisse raisonnablement blâmer dans l'usage de pareils livres. Cependant, il est très déplorable que pour cette raison, la concorde entre les membres de votre clergé ait été détruite et que les esprits ne se soient pas peu échauffés. Toujours, et aujourd'hui plus que jamais, les catholiques et surtout les ecclésiastiques, loin de soulever et d'entretenir des discussions fâcheuses, doivent employer tout leur zèle et leurs efforts à défendre la vérité catholique et à combattre pour la défense des droits de la Sainte Eglise, qui est si vivement attaquée. C'est pourquoi cette Sacrée Congrégation vous exhorte fortement dans le Seigneur à amener tous ces ecclésiastiques, en usant d'autant d'énergie que de charité pastorale, à proclamer la même chose en union de cœurs, et à ne faire qu'un par la conformité de vues et de sentiments. Elle vous exhorte en outre à faire en sorte, qu'ayant en horreur de vaines discussions, ils s'occupent avec zèle et dévouement des intérêts de Dieu et du prochain. On ne doute pas, en égard à votre prudence, que vous ne cessiez jamais de veiller à l'accomplissement de ce devoir de salut. Sur ce, je prie Dieu qu'il vous accorde bonheur et prospérité. ") (Traduit du latin par George St. Aimé).

Cette lettre du cardinal Patrizi est du 15 février 1867. Le 14 mars suivant, Mgr Baillargeon la communiquait à son clergé, dans une circulaire ${ }^{9}$, où il concluait que les idées gaumistes étaient condamnées

9. Mandements des évêques de Québec, IV, 564-571. 
et qu'il n'était plus permis de les soutenir. Mgr Gaume, ayant pris connaissance de cette circulaire, qu'avait reproduite un journal de Paris, écrivit alors, dans le Monde, du 16 mai 1867, que tel n'était pas le cas, et que, bien au contraire, la réponse du Saint-Office était une solennelle approbation de la thèse qu'il avaitsoutenue ${ }^{10}$. De son côté, George St. Aimé publia une seconde brochure: Lettre à Monseigneur Baillargeon, évêque de Tloa, sur la question des classiques et commentaire sur la lettre du cardinal Patrizi. Il y opposait un démenti et une fin de non-recevoir aux prétentions de l'évêque. Voici d'abord comment il justifiait sa précédente brochure, La Méthode chrétienne, trouvée injurieuse à l'autorité ecclésiastique et aux maisons de haut enseignement: ( J'ai pu, je l'avoue, émettre dans cette brochure des opinions qui ne sont pas les vôtres; mais les opinions d'un évêque, si respectables qu'elles soient, ne lient personne, pas même ceux qui sont soumis à sa juridiction épiscopale. Et comment ses opinions pourraient-elles lier quelqu'un, quand celles mêmes du Souverain Pontife ne font aucunement loi? Remarquez, s'il vous plaît, Monseigneur, que je dis opinions et non pas décisions (p. 4). C'est à l'autorité épiscopale à opérer la réforme désirée et sollicitée, j'en conviens et je n'ai jamais dit le contraire; mais, parce que c'est là son droit, s'ensuit-il que c'est lui faire injure que de lui proposer cette réforme, de lui en faire envisager les avantages, de réfuter les objections qu'opposent les adversaires, et même de donner de sévères leçons à ces derniers, s'ils les méritent par une conduite peu loyale? Je ne crois pas, Monseigneur, qu'on puisse raisonnablement l'affirmer. L'autorité et l'autorité seule a le droit de l'initiative quand il s'agit de l'action; je le soutiens et je blâmerais celui qui prétendrait le contraire. Mais s'agit-il de provoquer cette action par des réclames ou un cri d'alarme, le plus humble des sujets de l'autorité a le droit de l'initiative, s'il se sent assez de force et de courage pour en user. Les réformes les plus importantes, qui ont réjoui davantage le cœur de l'Eglise, n'ont-elles pas été presque toutes provoquées par de très humbles personnages, obscurs jusqu'alors? (p. 5). Ah ! Monseigneur, si ma brochure a pu vous laisser croire que je ne respecte pas l'autorité ecclésiastique, veuillez me permettre de proclamer hautement aujourd'hui que je la respecte et que je l'aime cette autorité... je voudrais la voir partout

10. Voir sa lettre dans la Minerve du 4 juin 1867. 
respectée, partout obéie. Je voudrais complètement en vigueur les saints canons et les règles disciplinaires du Concile de Trente; je voudrais que tous les collèges et séminaires fussent constitués et organisés conformément à ce que veut ce saint Concile; je voudrais que toutes les communautés religieuses, celles de filles surtout, eussent des constitutions et des règlements d'accord avec ce que prescrit le droit canonique, dont l'autorité, hélas! s'efface beaucoup trop souvent devant celle de quelque personnage qui veut avant tout voir régner le simple bon sens ${ }^{11}$; je voudrais que les règles de l'Index fussent regardées comme strictement obligatoires, puisqu'elles le sont réellement, qu'elles fussent en vigueur, surtout dans les Séminaires et les Universités catholiques; que là il ne fût plus permis de mettre des auteurs censurés entre les mains des élèves, d'enseigner dans les chaires du Droit des propositions condamnées par l'Église, de laisser les élèves de Médecine étudier dans des auteurs protestants ou dans des traités composés au point de vue du plus grossier matérialisme. Tels sont mes vœux les plus ardents, Monseigneur, et j'ai la bien consolante certitude que je les forme en union de cœur avec vous" (pp. 5-6).

Quant au reproche d'avoir injurié les maisons de haut enseignement, il répondait qu'à peu près toutes avaient fort bien accueilli sa brochure, l'une d'elles en particulier, celle de Saint-Hyacinthe, par son supérieur, "le très distingué et très savant M. le G.-V. Raym ınd " ${ }^{12}$. " Je sais fort bien que la plus ancienne 'e ces maisons s'es' montrée d'assez mauvaise humeur à l'apparition a cette brochure; $\mathrm{r}$ tis enfin, de quoi a-t-elle tant à se plaindre, elle c i a ouverterien persécuté et sur une grande échelle? ») (p. 6)

Mgr Baillargeon avait aussi relevé, dans la brochure La Méthode chrétienne, des propositions non seulement hasardées, mais encore tout à fait répréhensibles, comme la suivante, à laquelle il trouvait une saveur protestante: "La première charité du chrétien, c'est l'amour

11. " Le Père Braun avait été chargé, à Québec, de rédiger des constitutions pour des communautés de filles, et il les avait rédigées conformément aux lois canoniques. Comme on s'y attendait un peu, M. Cazeau ne les trouva pas conformes au bon sens. "Luigi, Il y a du libéralisme et du gallicanisme en Canada, 33. (Note de l'auteur)

12. M. Raymond était un gaumiste avant la lettre. Dès 1835 , il avait déploré publiquement la domination du paganisme dans l'enseignement classique. En 1847, il avait proclamé l'opportunité d'y introduire les Saints Pères. Cf. C.-P. Choquette, Histoire du Séminaire de Saint-Hyacinthe, I, 423. 
de la vérité... Un chrétien, quel qu'il soit, fût-il même le dernier d'entre ses frères, s'il est convaincu que l'intérêt de la vérité et de la foi exige qu'il parle, il parlera. " George St. Aimé explique le sens de cette proposition, en rapproche d'autres semblables émanant de Bossuet et de Bourdaloue, et se réserve le malin plaisir de déclarer, à la fin, qu'elle a été extraite textuellement d'un opuscule du P. Ramière, S.J., De l'Unité dans l'enseignement de la philosophie. "A la page 30 de cet opuscule, vous pourrez lire, Monseigneur, cette proposition que vous avez trouvée si mal sonnante dans la Méthode chrétienne " (p. 7).

(" D'ailleurs, ce que j'ai écrit, je l'ai écrit avec conviction, après de longues et sérieuses études. Je n'ai rien inventé, ni principes, ni faits. Les principes, je les ai puisés dans les Pères de l'Église, dans les conciles, dans l'encyclique Inter multiplices, dans les écrits authentiques des plus illustres cardinaux, archevêques et évêques de la Ste Eglise. Ces sources, Monseigneur, j'en ai l'intime conviction, vous les respectez autant que je les respecte moi-même. Quant aux faits, les uns étaient du domaine de l'histoire et de la critique, et il n'était au pouvoir de personne d'en anéantir l'existence ou la portée; les autres sont contemporains; ils viennent de se passer sous nos yeux ${ }_{2}$ et j'ai pu dire avoir vu ce que chacun a vu. D'après cela, Monseigneur, la Méthode chrétienne ne peut donc être si répréhensible; ce qui me confirme dans cette opinion, c'est que bien que dénoncée par vous au tribunal du St. Office, elle n'a reçu aucune note flétrissante. J'aime à dire cela de suite, car tous ne savent peut-être pas que lorsqu'un livre est dénoncé au St. Office, on donne aux propositions mauvaises, s'il en 'contient, les notes ou qualifications qui leur conviennent)" (p. 3).

Après ces propos impertinents et ces allusions malignes, il en arrivait à l'examen de la lettre du cardinal Patrizi. "Veuillez relire, s'il vous plaît, Monseigneur, tout ce qui a été écrit sur la méthode chrétienne depuis deux ans, et vous demeurerez convaincu que nous n'avons pas parlé autrement que le cardinal Patrizi... les partisans de la réforme chrétienne dans l'enseignement sont en parfait accord avec le cardinal Patrizi: leurs écrits ne sont que le rigoureux développement des règles qu'il pose avec tant de sagesse (p. 13).

"Son Eminence dit que vous lui donnez l'assurance que dans votre séminaire et vos collèges les auteurs païens sont parfaitement expurgés... Qu'on abuse étrangement de la confiance et de la bonne 
foi de Votre Grandeưr ! Votre séminaire a donc deux éditions classiques? l'une parfaitement expurgée, qu'il étale dans les grandes circonstances et dont il ne fait aucun usage hors de là; l'autre, non expurgée, qu'il laisse entre les mains de ses élèves et qui leur sert de pain quotidien. Je le comprends, Monseigneur, vous avez peine à m'en croire. Eh ! bien, j'ose vous le suggérer, faites-vous, s'il vous plaît, remettre les classiques en usage dans votre séminaire en l'an de grâce 1867, et vous verrez si je dis vrai. En attendant, je prendrai la liberté de mettre sous les yeux de Votre Grandeur quelques extraits de ces auteurs prétendus expurgés, ab omni labe purgati ") (p. 14).

Et il passait en revue: Virgile ${ }^{13}$, " qu' on affectionne par-dessus tous les autres, qui fait, on peut dire, le fond des études littéraires et qu'on laisse entre les mains des élèves pendant trois longues années et généralement pendant quatre » (p. 15); Horace, " qui, dans les classes, tient la première place après Virgile..., que savourent les élèves des classes de Belles-Lettres et de Rhétorique ) (p. 18); Cicéron, " qui, au dire de certains dévots païens, parle quasi comme un Père de l'Église ) (p. 21), Salluste, Phèdre, Cornélius-Népos et Homère.

Dans sa circulaire, Mgr Baillargeon avait clairement donné à entendre que, après la lettre du cardinal Patrizi, les questions qu'il avait posées au Saint-Office ne pouvaient plus être discutées à l'avenir. George St. Aimé prétendait le contraire. "Je serais véritablement heureux d'être ici parfaitement d'accord avec Votre Grandeur; mais impossible, Monseigneur, impossible! Toutes ces propositions, en effet, que vous numérotez, vous les mettez en regard d'autres propositions, extraites de la lettre du cardinal Patrizi, comme en étant les contradictoires, et cependant il me semble qu'elles ne s'y rapportent pas pour la plupart ") (p. 28). Et, après l'avoir démontré, il concluait: " De tout ce que j'ai dit jusqu'ici, et je le crois bien appuyé, il résulte, Monseigneur, que la réponse que vous avez reçue de Rome laisse le champ parfaitement libre aux partisans de la méthode chrétienne, mais non pas à leurs adversaires (p. 32). La lettre du cardinal Patrizi est un nouveau motif d'encouragement pour nous, puisqu'elle confirme pleinement ce qu'ont écrit en Canada et en France les zélés promoteurs de la réforme dans l'enseignement littéraire. Si les circonstances le demandent encore, nous serons en droit par conséquent d'élever la voix comme par le passé; bien plus, ce sera pour nous un devoir, car que peut-on faire de plus utile, de plus agréable à Dieu et à sa Sainte

13. Sans oublier l'inclination du berger Corydon pour le bel Alexis. 
Eglise, que de proclamer ce qu'elle proclame, de déclarer interdit ce qu'elle interdit? ») (p. 38).

L'abbé Thomas Chandonnet, qu'on avait envoyé étudier à Rome en 1865, en était revenu en 1867, avec trois doctorats, ceux de philosophie et de théologie du Collège Romain et celui de droit canonique de l'Apollinaire, et avait été nommé principal de l'École Normale de Québec. Il se mit à faire des conférences. Dans l'une d'elles, intitulée Quelques mots de Rome, il s'en prenait à la Lettre à Monseigneur Baillargeon sur la question des classiques, " une brochure, disait-il, qu'il eut fallu brûler sur la place publique, si elle eut seulement mérité de passer par le feu. " ${ }^{1}$ Piqué au vif, George St. Aimé rédigea sa Réponse aux dernières attaques dirigées par $M$. l'ábbé Chandonnet contre les partisans de la méthode chrétienne, un des plus méchants écrits sortis de sa plume ${ }^{15}$.

Il ne se refusait pas le facile plaisir de ridiculiser le triple bonnet de docteur de son adversaire. "En deux ans, quoiqu'on ait déjà été préparé par certaines études, on ne peut faire qu'effleurer, quand le champ est aussi vaste que l'est celui de la philosophie, du droit canon et de la théologie. Les trois doctorats de M. l'abbé Chandonnet ne sons plus ni moins que des certificats de bonnes études élémentaires. Il y a bonnets et bonnets; la coiffure de M. l'abbé n'est pas d'un triple airain... Peu se sont laissé prendre au piège, et l'illusion eut-elle été possible pendant quelque temps, que M. l'abbé Chandonnet l'eût complètement détruite par la publication de ses récents travaux

14. L'Événement, 30 avril 1868.

15. Le numéro d'aoât 1867 des Annales de philosophie chrétienne (38e année, 5e série t. XVI, 102-152) contient une longue lettre adressée à leur directeur, A.' Bonetty, par un correspondant qui signe L.S.J., et prudemment datée "Canada 1867". Il y a tout lieu de croire que cette lettre provient de l'abbé Pelletier (Cf. Gazette des campagnes, 3 fév. 1870 p. 358). On y trouve les divisions, l'analyse et de longs extraits de la Methode chrétienne de George St- Aimé, le texte de la circulaire de Mgr Baillargeon du 14 mars 1867, l'analyse et des extraits de la Lettre à Monseigneur Baillargeon de George St. Aimé, la lettre de Mgr Gaume parue dans le Monde du 16 mai 1867 au sujet de la réponse du cardinal Patrizi à Mgr Baillargeon, et une lettre de Mgr Dupanloup à un monsieur de Québec (l'abbé Benj. Pâquet, d'après Mgr Gaume, Cf. Nouveau-monde, 29 déc. $1869 ;$ Minerve, 15 déc. 1869), publiée dans le Journal de Québec du 4 juin 1867. - Le numéro de janvier 1869 des mêmes $A n$ nales (39e année, 5e série, t. XIX, 7-32) contient une nouvelle lettre du même correspondant canadien $L . S . J$. , qui critique les conférences philosophiques de l'abbé Chandonnet et donne un résumé et des extraits de la Réponse aux dernières attaques par George St. Aimé. - Les conférences de l'abbé Chandonnet avaient paru dans l'Evénement: 30 déc. $1867 ; 7,13,14$ janv., 23 et 30 avril 1868. 
(p. 6). Que M. l'abbé nous permette donc de le lui dire franchement: tout cerveau, fonctionnât-il sous l'égide d'un triple bonnet, doit coordonner et accorder ses idées avant de leur laisser voir le jour " (p. 12).

Mais il y avait beaucoup plus grave. Dans cette brochure, George St. Aimé ne se contentait pas de démolir les avancés du " savantissime confabulateur ", il faisait des révélations sensationnelles. Il y publiait, avec commentaires, des documents authentiques qui jetaient une lumière crue sur les machinations des abbés Thomas Chandonnet et Benjamin Pâquet pour faire condamner par Rome la Méthode chrétienne. Dans sa Lettre à Monseigneur Baillargeon, il avait insinué que plusieurs passages de la circulaire avaient été inspirés par d'autres personnes, qui avaient abusé de sa confiance et de sa bonne foi. Il affirmait maintenant que l'évêque n'avait fait guère autre chose que de signer une pièce cuisinée par MM. Chandonnet et Pâquet, et il le prouvait en produisant le texte de deux lettres écrites de Rome par Chandonnet à Pâquet, une du 17 octobre 1866 et une autre du 22 octobre de la même année.

Dans ces deux lettres, Chandonnet confiait à son correspondant les démarches qu'il avait faites auprès de certains professeurs du Collège Romain et indiquait la tactique à suivre. On avait conseillé de ne pas s'adresser à la Congrégation de l'Indey, parce que trop indulgente " et que les influences s'y font sentir tr , p puissamment ", mais au Saint-Office. Il lui envoyait une liste de propositions, qu'il avait rédigées en latin et qui lui paraissaient emk asser " tout le gaumisme présent et futur », et il suggérait « que $M$ nsseigneur l'Administrateur lui-même présentât ces propositions, en se plaignant du mal que ces idées font dans la province ecclésiastique ou dans son diocèse. " Il lui envoyait " même un modèle de pétition où Monseigneur n'aurait qu'à faire la partie qui regarde le mal produit. Puis qu'il ajoute que je suis chargé de passer au Secrétaire les brochures et les références désirables... Je tâcherai de me passer de celles où paraissent trop clairement les noms de Messeigneurs Filippi et Gaume "). Inutile de dire qu'il recommandait le silence le plus absolu sur cette affaire.

George St-Aimé confrontait les propositions rédigées par Chandonnet et les questions posées par Mgr Baillargeon au Saint-Office: elles étaient identiques pour le fond et se suivaient dans le même ordre. Il terminait en rassurant sa conscience. "Les lettres de M. l'abbé 
Chandonnet, que nous avons en notre possession, n'ont pas été frauduleusement extorquées; c'est la Providence qui les a mises entre les mains de ceux qui nous les ont fait parvenir. Qu'on ne nous reproche pas de les avoir rendues publiques: il n'y avait pas de secret naturel à garder en pareil cas, car c'est pour tout homme un devoir de dévoiler les complots formés en haine de la justice et de la vérité » (p. 56).

Cette brochure fut répandue partout en même temps, le 27 juillet 1868. Le 12 août suivant, l'archevêque publia un mandement ${ }^{16}$ (rédigé par M. Taschereau, prétend M. Pelletier) pour condamner les deux brochures de George St-Aimé: Lettre à Monseigneur Baillargeon et Réponse aux dernières attaques dirigées par $M$. l'abbé Chandonnet. Parlant de cette dernière, il écrivait: " Sous prétexte de répondre à des attaques dirigées contre un système qu'il affectionne, l'auteur, caché sous un faux nom, déverse l'injure et la calomnie contre deux prêtres honorables, et occupant des places de confiance, sous notre autorité, dans notre diocèse; porte atteinte à notre autorité épiscopale, qu'il avait déjà méconnue ouvertement dans une brochure précédente, et stigmatise, comme propre à faire revivre le paganisme dans l'Église, un système d'enseignement qu'il sait bien être tout à fait permis par le Saint-Siège et suivi dans tous les pays catholiques et jusque dans les murs de Rome... Que dirons-nous de l'acte malhonnête et indigne d'un homme d'honneur, par lequel l'auteur s'est emparé directement ou indirectement de lettres privées pour les rendre publiques? Nous laissons à la conscience des honnêtes gens à juger de ce procédé, que le même auteur ose appeler légitime et providentiel. Nous ne dirons rien des interprétations fausses et calomnieuses données à ces lettres. Nous devons seulement en justice à Monsieur Chandonnet de déclarer que nous l'avions chargé, par l'entremise de Monsieur Benjamin Pâquet, de voir auprès des Congrégations Romaines, quels moyens il fallait prendre pour mettre un terme efficace à des discussions qui ne pouvaient que faire du mal. Ces deux prêtres n'étaient donc pas des intrigants, ni des cabaleurs, ni des conspirateurs se jouant de la vérité et de leur archevêque, comme l'a prétendu l'auteur de la brochure. ")

Sous peine de désobéissance grave et d'excommunication $f e$ rendae sententiae pour les laïques et de suspense ipso facto pour les

16. Mandements des evêques de Québec, IV, 646-648. 
membres du clergé, l'archevêque défendait de lire, prêter et garder ces deux brochures - il enjoignait même de les brûler dans les trois jours-; de ne rien publier sur cette question des classiques sans sa permission, de ne contribuer en rien à la publication de nouveaux écrits sur ce sujet, même en dehors du diocèse, et même de lire ou de garder des écrits qui se publieraient ailleurs sans l'approbation de l'Ordinaire du lieu; enfin il enjoignait à l'auteur ou aux auteurs des deux brochures de réparer, dans les trente jours, le scandale et le tort causé au prochain.

M. Pelletier n'en fit rien. Après avoir consulté plusieurs théologiens et canonistes éminents, dont l'abbé Stremler, Mgr Gaume et Mgr Filippi, il jugea que les peines portées contre lui étaient nulles et que, n'étant pas connu comme auteur des brochures condamnées, la raison du respect et de la soumission dûs à l'autorité ne l'obligeait point à se conduire publiquement comme censuré. Bien plus, il porta secrètement plainte au Saint-Office, par l'entremise de Mgr Filippi, contre Mgr Baillargeon. Ce dernier cessa, quelque temps après, de tenir aux prescriptions de son mandement. On sut, par la suite, qu'il avait reçu du Saint-Office un monitum blâmant la sévérité de son mandement, que le cardinal Barnabo, préfet de la Propagande, avait crtiqué ce même mandement en présence de prêtres et d'évêques canadiens ${ }^{17}$.

M. Pelletier redevint joc. naliste. Il se publiait, à Sainte-Anne de la Pocatière, une petite feunie hebdomadaire, la Gazette des Campagnes, qui, aux côtés du Nouveau-Monde de Montréal et du Journal des Trois-Rivières, donnait la chasse au libéralisme catholique français anti-infaillibiliste et aux sympathies qu'il recueillait dans les journaux de notre province. Or, vers la fin de 1868, Mgr Dupanloup ayant adressé à Mgr Baillargeon deux exemplaires de sa Lettre sur le futur Concile oecuménique, avec ces mots écrits de sa main: Hommage de l'auteur, l'ạrchevêque de Québec avait fait imprimer la pièce et l'avait donnée en étrennes aux prêtres de son diocèse. M. Pelletier écrivit à Mgr Gaume pour savoir quel jugement il convenait de porter sur elle. Dans sa réponse, Mgr Gaume rapporta les paroles mêmes qu'il tenait de Mgr Chigi, nonce apostolique à Paris: "Cette Lettre

17. Cf. Nouveau Monde, 3, 11 et 13 déc. 1872; et Franc-Parleur, 4 janv. 1873; 1er, 19 et 26 sept. 1876 . 
est peu de chose; on y plaide les circonstances atténuantes en faveur de l'esprit moderne. " M. Pelletier inséra cette appréciation dans un article de son journal (18 nov. 1869). Le G.-V. Cazeau vit dans ce geste un blâme infligé indirectement à Mgr Baillargeon, alors parti pour le Concile, blâme d'autant plus grave que le journal était publié sous les auspices d'une institution chargée d'élever la jeunesse, et surtout les élèves du sanctuaire, et dont, par conséquent, le devoir était de leur inculquer le respect et la soumission à l'autorité du premier pasteur. Le 22 novembre 1869, il écrivit au Supérieur de SainteAnne, M. Pilote: "Comme il est de mon devoir de porter l'article en question à la connaissance de Mgr l'archevêque, je vous prie, M. le Supérieur, de vouloir bien me faire savoir au plus tôt s'il a été publié du consentement des membres de la Corporation du Collège; si, dans le cas où il l'aurait été à leur insu, ils entendent déclarer, dans la même feuille, qu'il a été publié sans leur participation et qu'ils regrettent sa publication; ou bien, s'ils préfèrent m'envoyer d rectement un désaveu dont je pourrai faire usage de la manière la plus convenable. $)^{18}$ Les prêtres de Sainte-Anne ne crurent pas devoir tenir compte de cette injonction, et $M$. Pelletier porta plainte à Rome.

Au même moment, un journal libéral de Québec, L'Événement ${ }^{19}$, reproduisait avec les plus grands éloges le fameux Manifeste du Correspondant de Paris. M. Pelletier combattit le Manifeste, et publia une série d'articles contre le libéralisme. Il eut avec le Journal de Québec une polémique des plus acerbes et qui dura des mois. L'Ordre de Montréal, comparait la lutte de la petite Gazette des Campagnes, ultramontaine, contre le puissant Journal de Québec, "dernier boulevard du gallicanisme dans le diocèse de Québec ), au combat de David contre Goliath ${ }^{20}$. Le Journal donnait à entendre que la Gazette avait changé son rôle et ne parlait pas assez d'agriculture, et il lui donnait ce conseil: "Occupez-vous donc de choux et de navets. " La Gazette répliquait (3 fév. 1870): "Nous ne les négligeons pas pourtant: depuis plus d'un mois nous travaillons dans son jardin. ) Le rédacteur du Journal, Joseph Cauchon, s'était rabattu sur le patron

18. Luigi, Il y a du libéralisme et du gallicanisme en Canada, 11.

19. 19-29 nov. 1869.

20. Cf. Gazette des Campagnes, 6 oct. 1870. 
de M. Pelletier, saint Alexis, à qui il reprochait d'avoir mis le divorce en honneur. (D'après la légende, saint Alexis, marié contre son gré, avait quitté en secret la maison paternelle, le jour même de ses noces) ${ }^{2} 1$ M. Pelletier lui rendit la monnaie de sa pièce: " M. l'écrivain du Journal de Québec, après s'être roulé quelque dix minutes dans la boue, préliminaires obligés des êtres de son espèce, en arrive à la question de l'infailibilité du Pape. " ${ }^{22}$ Il regretta, dans son article suivant, cette allusion au nom de Cauchon.

L'abbé Louis Proulx, vicaire général du diocèse, mais que $M$. Cazeau avait fait reléguer à Sainte-Marie de Beauce, écrivait, au début de 1870, à un de ses confrères, en parlant de l'intrépide rédacteur de la Gazette des Campagnes: " Dites donc à ce jeune Monsieur que je lui conseille de cesser, au moins pour un temps, de défendre la vérité, s'il tient à se conserver. Si, malgré mon conseil, il continue, dans la voie où il est entré, je louerai son courage comme héroïque, car il doit savoir que la Beauce est une colonie pénale ") ${ }^{3}$. M. Pelletier s'entêta, et ce qui était prévu arriva. Le 20 mai, il reçut de Mgr Baillargeon, de retour du Concile du Vatican, l'ordre de quitter le Collège de Sainte-Anne, et d'aller remplir les fonctions de vicaire à Saint-Joseph de Beauce. Un tel changement, à une telle époque de l'année, équivalait à une punition aux yeux du public. Il se crut gravement lésé et en appela à Rome. Il ne se rendit pas à Saint-Joseph de Beauce, jugeant que son appel avait un effet suspensif, d'après les canonistes et en particulier l'abbé Stremler, dans son Traité des peines ecclésiastiques $^{24}$, mais, il alla se fixer chez un ami, le curé Louis-Napoléon Cinq-Mars ${ }^{25}$, de Saint-Fidèle, comté de Charlevoix, et il continua d'écrire dans la Gazette des Campagnes. Les journaux, l'appelaient ( le solitaire de Saint-Fidèle ».

Mgr Baillargeon communiqua, dans une circulaire du 31 mai ${ }^{26}$, une consultation de Mgr De Angelis, sur notre Code civil, jugé anti-

21. Ibid., 3 fév. 1870.

22. Ibid., 10 mars 1870.

23. Luigi, Il y a du liberalisme..., 32.

24. Gazette des Campagnes, 29 sept. 1870.

25. Nouveau-Monde, 30 janv. 1873 (lettre du curé Cinq-Mars au chanoine $\mathrm{G}^{*}$ Lamarche).

26. Mandements des évêques de Québec, IV, 719-725. 
catholique par les ultramontains. La Gazette des Campagnes reproduisit alors (9 juin) un article du journal Hausbloeter contre des évêques allemands qui avaient blâmé certains abbés d'avoir écrit sur des questions ayant trait aux rapports entre l'Eglise et l'Etat, sous prétexte qu'ils l'avaient fait sans mission et sans autorité. On y lisait: « C'est ainsi, par exemple, qu'on les voit consulter quelque théologien ou canoniste de renom, mais dont la parole est loin d'être infaillible, et, sur les réponses faites à leurs exposés plus ou moins fidèles de l'état des choses, tirer des conclusions tout à fait illégitimes ). Mgr Baillargeon en fut indigné. Profitant de leur désaccord sur la question financière avec leur Supérieur, M. Pilote, il exigea que les partisans de M. Pelletier qui étaient membres de la corporation légale et civile du Collège de Sainte-Anne lui donnassent par écrit leur démission comme tels. Ils refusèrent, disant qu'ils en appelaient à Rome. Il leur écrivit (2 août): "Votre appel au Pape ne vous soustraira pas à l'autorité de votre Archevêque; c'est tout simplement une fanfaronnade ridicule, qui ne saurait vous mettre à l'abri des peines et des censures que vous auriez méritées par votre rébellion ». Ils appelèrent de la menace de censure; puis ils s'efforcèrent, au cours d'une longue discussion qu'ils eurent à soutenir par lettres avec le vénérable prélat, de l'amener à modifier ses manières de voir et d'agir. Il consentit à se désister de ses prétentions, mais à la condition qu'ils désavoueraient par écrit les articies de M. Pelletier dans la Gazette des Campagnés; ce qu'il firent dans les termes suivants: « Nous regrettons et désavouons tout ce qui aurait pu blesser Votre Grandeur dans notre correspondance avec Elle ou dans la Gazette des Campagnes, notamment dans l'article du Hausbloeter, et nous déclarons cesser dès à présent toute relation avec cette Gazette ) (26 août 1870) ${ }^{27}$. Mgr Baillargeon étant revenu de Rome malade, cette affaire ne put que contribuer à aggraver son état. Il mourut quelques semaines après, le 13 octobre 1870. Il eut pour successeur l'abbé Elzéar Taschereau.

M. Pelletier avait déjà pris des mesures pour échapper à la vindicte de l'ancien recteur de Laval. Dès 1868, par l'entremise de Mgr Filippi, il avait demandé au Saint-Siège la permission de passer au

27. Dans La Source du Mal de l'Epoque, p. 48, M. Pelletier leur prête cette restriction: "Nous désavouons dans ces écrits tout ce qui a pu raisonnablement constrister Mgr l'Archevêque ". 
diocèse de Rimouski, érigé l'année précédente et où se trouvait sa paroisse natale, Cacouna. Après bien des instances de la part de Mgr Langevin, le cardinal Barnabo répondit, le 2 septembre 1871, que M. Pelletier pouvait aller à Rimouski, pourvu que l'évêque de ce diocèse lui accordât une charge ou un bénéfice convenable. M. Pelletier se vit confier les missions les plus lointaines; mais, au bout de quelques mois, invoquant son peu de santé, il demanda la faculté de passer dans un autre diocèse ${ }^{28}$. Après un échec auprès de Mgr Laflèche, des Trois-Rivières, il s'adressa à l'évêque de Montréal, qui voulut bien l'accepter. En envoyant son exeat, Mgr Langevin confiait à Mgr Bourget (3 août 1872): " Je ne puis m'exempter en conscience de déclarer confidentiellement à V. G. que j'ai bien des raisons de le considérer comme un esprit orgueilleux et exalté, pouvant, surtout dans certaines positions, faire grand mal à la Religion, en semant la division dans le clergé, et sapant par la base l'autorité épiscopale. C'est en majeure partie ce qui me détermine à renoncer aux services de ce jeune prêtre, malgré les urgents besoins de mon diocèse, et malgré les talenis dont il est incontestablement doué.- Je dois ajouter que, le 15 mai dernier, Mgr Laflèche m'écrivait que « ce projet (de recevoir Mr P. dans son diocèse et de lui donner de l'emploi) ayant percé dans le public, plusieurs prêtres du diocèse ont craint qu'il n'en surgît quelques désagréments s'il se réalisait dans les circonstances actuelles, et m'ont prié de vive voix et par écrit de n'y point donner suite. Après avoir pris l'avis de mon Conseil, j'ai dû en venir à la conclusion qu'il fallait y renoncer... ) Mgr Bourget passa outre aux appréhensions de son collègue et assigna son nouveau sujet au poste de vicaire de Saint-Henri des Tanneries et de chapelain des Sœurs de Ste Anne du même endroit.

M. Pelletier s'était réfugié dans le diocèse de Montréal, non pour vivre en paix, mais pour continuer la lutte, sous la houlette d'un pasteur dont les idées, sinon le tempérament, s'accordaient bien avec les siennes. Il ne tarda pas à se signaler par quelque action d'éclat. Ce fut à l'occasion des noces d'or de Mgr Bourget. On sait que, en cette circonstance, le P. Braun, S.J., prononça, dans l'église Notre-Dame, un sermon offensant pour les évêques présents et pour les Sulpiciens eux-mêmes. L'audacieux jésuite, récemment éloigné de Québec pour

28. Franc-Parleur, 16 nov. 1872 et 29 août 1876. 
avoir combattu les erreurs gallicanes de Pothier dans un carême prêché à la Cathédrale, s'était permis d'aborder tous les sujets de la plus brûlante actualité: législation matrimoniale, érection des paroisses, influence spirituelle indue, etc., pour en arriver à féliciter l'évêque de Montréal d'avoir combattu en ces matières les deux fléaux du gallicanisme et du libéralisme. Ce qu'on sait moins, c'est que M. Pelletier avait prêché à la Cathédrale, le premier jour des fêtes jubilaires, le dimınche précédent, 27 octobre. Voici comment les choses s'étaient. passées. Le samedi, veille de la fête organisée par le Chapitre, on apprit que Mgr Laflèche, qui devait prendre la parole à Notre-Dame, ferait défaut. Vu ce contre-tẹmps, on pria le P. Braun de se réserver pour la fête du mardi à Notre-Dame et l'abbé Pelletier, qui avait la parole facile, accepta de le remplacer à la Cathédrale. Au moment de la grand'messe, arriva Mgr Taschereau, archevêque de Québec. Il avait pris le bateau du samedi pour arriver le dimanche. Après avoir célébré la messe à Notre-Dame de Pitié, il avait décidé d'assister aussi à la fête qui avait lieu à la Cathédrale, où il n'était pas attendu. M. Pelletier apprit l'arrivée de Mgr Taschereau seulement quelques. instants avant de monter en chaire; mais l'archevêque ne connut le prédicateur du jour qu'en se trouvant en sa présence. "J'assistais moi-même à cette instruction, raconte l'abbé Pierre Poulin. L'abbé, en parlant de Mgr Bourget, semblait prendre plaisir à faire ressortir le contraste qu'offrait ce pieux prélat qu'on fêtait et l'archevêque de Québec, qu'il savait fort bien désigner. Il insista surtout en louant dans l'evêque de Montréal sa doctrine ultramontaine bien connue. Loin de craindre, dit-il, comme on l'a vu ailleurs, il attaque toutes. les erreurs, et ne redoute pas d'encourager ceux qui proclament la vérité. Ce propos et autres semblables durèrent près de 40 minutes. ") ${ }^{2} 9$

Les journaux libéraux relevèrent le scandale. Le rédacteur du Canadien de Québec, Lucien Turcotte, protesta contre le choix des prédicateurs (4 nov.): "Nous avons entendu, comme tout le monde, le malheureux sermon du R. P. Braun, jésuite; comme tout le monde aussi nous étions demeuré stupéfait de tant d'inconvenance dans une circonstance ou la première règle à observer était, ce nous semble, celle de la plus grande délicatesse. Nous avions appris en outre qu'un sermon avait été prêché à la cathédrale, le dimanche précédent, en

29. A. Savaëte, Voix canadiennes: Vers l'abîme, IX, 352-353. 
présence de l'archevêque de Québec et de l'évêque de Rimouski, par le prêtre même qui vient de quitter les diocèses de ces deux prélats dans les circonstances pénibles que tout le monde connaît, M. l'abbé Alexis Pelletier, ex-rédacteur de la Gazetté des Campagnes, et auteur reconnu des brochures libelles publiées sous le pseudonyme de George Saint-Aimé. Ce double choix nous parut déjà une insulte lancée à l'archevêque et à l'évêque de Rimouski. "

M. Pelletier lui répondit, dans le Franc-Parleur (16 nov.): " A aucun titre vous n'avez à vous prononcer sur la convenance ou la nonconvenance qu'il y a pour moi de monter en chaire dans telle ou telle église. C'est l'affaire de mon supérieur ecclésiastique, contre lequel vous péchez par insolence... Quant à George St. Aimé, dont vous dites aussi un mot, je crois devoir vous informer qu'à Rome on ne le regarde pas du tout d'un mauvais œil. J'ai en ma possession plus d'un document qui l'atteste. Dans les tristes affaires que la question des classiques a soulevées parmi nous, Rome n'a blâmé que ceux qui ont cru devoir sévir contre George St. Aimé. Si encore là-dessus vous voulez de pius amples détails, je suis disposé à vous satisfaire. " Comme le Journal de Québec le défiait de prouver ses avancés, il écrivit, dans le Franc-Parleur (4 janv. 1873): "Si l'homme du Journal... veut avoir des renseignements véridiques sur ce que Rome a décidé relativement aux brochures de St. Aimé et aux censures publiées, qu'il se fasse introduire dans certaines Archives et là, dans le vol. No. Année 68 et 69 , il pourra lire de ses propres yeux le Monitoir adressé au défunt archevêque Baillargeon ").

L'incident des noces d'or n'était pas encore clos que M. Pelletier était reparti en guerre contre le libéralisme. Dans le Nouveau-Monde, considéré comme l'organe officieux de l'évêché de Montréal, il avait publié, sous le pseudonyme de $A$. de $F$., une série d'articles, qui furent réunis en une brochure: Quelques observations critiques sur l'ouvrage de M. l'abbé B. Pâquet intitulé: Le Libéralisme ${ }^{30}$. Sans violence de langage, il reprochait au professeur de Laval d'avoir donné une définition incomplète, rendant bien les vrais caractères du libéralisme impie, mais ne disant rien du libéralisme " si fort caressé de nos jours »,

30. Cet opuscule renfermait les cinq dernières leçons du cours public de Droit naturel et des gens donné à l'Université Laval par l'abbé Pâquet, au printemps de 1872 . 
le libéralisme catholique; et il protestait contre sa manière de comprendre la paix et contre le mode dont il prétendait que Notre-Seigneur, ses Apôtres et l'Église l'ont pratiquée. Certains journaux lui ayant opposé un article élogieux de la Civilta-Cattolica des Jésuites de Rome sur l'opuscule de M. Pâquet, il répliqua, sous son vrai nom, dans le Nouveau-Monde (14 nov. 1872): " On m'a informé dans le mois d'août dernier que M. l'abbé B. Pâquet, pour se tirer d'embarras avec son opuscule sans avoir recours à la science ni à la logique, tâcherait d'obtenir de quelqu'un de ses professeurs d'autrefois à Rome, à titre d'ancien élève qui mérite encouragement, une bonne note en faveur de ce travail. On ne m'a pas trompé: l'article de la Civilta nous arrive au temps annoncé et il porte bien plutôt le cachet d'un acte de pure courtoisie que celui d'une critique sérieuse. Ce qui prouve évidemment que M. Pâquet et ses amis ont fait de leur mieux pour provoquer les éloges que la savante Revue décerne au Libéralisme, c'est qu'il y en a à foison; ils pleuvent à droite et à gauche sur des personnes et des choses qui n'entrent pas naturellement dans le cadre de la question à traiter. Ce n'est pas ainsi qu'a coutume de procéder la Civilta quand elie fait sérieusement de la critique. Mais, quoiqu'il y ait eu de petites intrigues, quelque chose d'un peu ressemblant aux manœuvres savamment ourdies auxquelles prit activement part M. l'abbé B. Pâquet quand un jour on tenta un suprême effort pour arracher au SaintOffice une condamnation de la méthode chrétienne d'enseignement, la Civilta ne s'est cependant pas compromise. Elle sait être bienveillante sans manquer au respect qu'elle se doit, sans blesser les droits de la vérité... La Civilta ne loue ni plus ni moins, dans cet opuscule, que ce que j'y ai moi-même loué... Comme M. l'abbé B. Pâquet a jugé à propos de faire en quelque façon intervenir dans notre débat des personnages qui jouissent à Rome d'une réputation de savoir bien méritée, je veux que l'intervention soit sérieuse. Aussi, leur enverrai-je prochainement, non pas seulement une partie des pièces dont ils ont besoin pour juger, mais toutes les pièces, et dans quelques mois, ceux qui voudront être de bonne foi, sauront au juste à quoi s'en tenir sur les passages que j'ai trouvés répréhensibles dans l'œuvre de M. l'abbé B. Pâquet. )

Puis, dans le Franc-Parleur du 15 février 1873: "Les cinq parties du monde, à peu près, si l'on en croit les communications dont la Minerve nous gratifie de temps à autre, ont envoyé leurs félicitations 
à M. l'abbé Benj. Pâquet, à l'occasion des cinq leçons qu'il a données à l'Université Laval sur le libéralisme... Le Pape même s'est ému au bruit que faisait à Rome l'opuscule de M. l'abbé Benj. Pâquet, et, pour témoigner à l'auteur toute sa satisfaction, il lui a envoyé sa bénédiction. Pour moi, j'ai tout lieu de penser que, si les choses continuaient de ce train, la brochure de M. l'abbé Pâquet ne tardera pas à être enrichie de nombreuses indulgences, mêmes plénières. Il pourrait bien arriver, cependant, que ces indulgences ne fussent applicables qu'aux libéraux revenus de leurs erreurs. " La polémique avec la Minerve se poursuivit pendant plusieurs mois ${ }^{31}$.

Encore en cet automne de 1872 , les Jésuites avaient présenté à la législature provinciale un bill les autorisant à fonder une université catholique à Montréal. L'Université Laval invoqua son monopole et proposa un plan suivant lequel ce seraient les mêmes facultés qui, à Québec et à Montréal, enseigneraient le Droit et la Médecine, sous son contrôle exclusif. Il s'ensuivit une polémique, à laquelle M. Pelletier ne manqua pas de prendre part. Sous le pseudonyme de Luigi ${ }^{32}$, il écrivit, dans le Franc-Parleur des 30 novembre et 7 décembre, deux longs articles sur la Question de l'Université ${ }^{3}$. Il y développait les raisons qui militaient contre le plan proposé: 1o la répugnance invincible que la plupart des jeunes étudiants de Montréal éprouvent à demander aux Messieurs de Québec le pain de l'intelligence; 2o l'impossibilité de trouver à Montréal des légistes ou des médecins qui veuillent s'astreindre à répéter les leçons que leur dictera l'Université Laval; 3o la grande impopularité qui pèse sur l'Université Laval, l'écrase et la menace d'une ruine complète et prochaine; et 40 la mauvaise qualité de l'enseignement que donne l'Université Laval.

" Pour le Droit, cet enseignement est celui des parlementaires et des gallicans, notamment du fameux Pothier, que les élèves de l'Uni-

31. L'abbé B. Pâquet publia à Rome, en 1877, une deuxième édition de son ouvrage, revue, corrigée et augmentée, et précédée d'un bref élogieux de Pie IX en date du 23 octobre 1876 et de l'appréciation que la Civilta Cattolica, par la plume de son directeur, le P. Cardella, en avait faite lors de sa parution. Cf. Revue de Montrél, I, (1877), 618-634.

32. C'était le prénom de Mgr Filippi.

33. Ces articles furent reproduits en appendice à la brochure Reponse au factum intitule "Quelques remarques sur l'Université Laval ", par la Rédaction du FrancParleur, 51-60. 
versité ont entre les mains, qu'ils doivent consulter comme la plus haute autorité dans la matière, et cela, quoique Pothier renferme des propositions si formellement condamnées par Pie IX qu'elles font encourir l'excommunication ipso facto à ceux qui gardent simplement en leur possession les livres, quels qu'ils soient, où elles sont formulées. Pour la Médecine, il est foncièrement matérialiste et athée; c'est là surtout qu'on fait de la science sans Dieu. Les élèves ont même entre les mains, avec approbation au moins de leurs professeurs, sinon d'après leurs recommandations, des livres qui recèlent plus d'une abomination. On y lit, par exemple, que les extases de S. Paul, de Ste Thérèse et de tous les autres, dont parle l'Écriture ou l'histoire ecclésiastique, ne sont ni plus ni moins que des maladies nerveuses (p. 57). Comment procède l'Université Laval dans l'enseignement du Droit et de la Médecine?... en véritable université athée, car cet enseignement, elle le donne absolument en dehors de toute religion. Elle veut par là se montrer libérale en rendant ses cours accessibles à tous les jeunes gens, quelles que soient leurs convictions religieuses (p. 58). Montréal veut une université, parce qu'il la veut franchement catholique, il a mille fois raison d'avoir cette volonté ") (p. 59).

Le Factum publié par l'Université Laval se terminait par quatre lettres des évêques de Rimouski, de Saint-Hyacinthe, d'Ottawa et de l'archevêque de Québec, favorables à son monopole (On en avait supprimé celle, défavorable, de Mgr Laflèche). M. Pelletier, prenant un autre pseudonyme, celui de l'Abbé Ste-Foi, écrivit dans le FrancParleur des articles de ton badin, qui forment les deux petites brochures: Les Quatre lettres. Croquis de topographie universitaire et Une Conversation faisant suite à la brochure "Les Quatre lettres.). "Les quatre lettres, disait-il, semblent se ressentir des circonstances particulières du lieu où elles ont été écrites. Il y a je ne sais quelle couleur locale qui se déteint sur chacune d'elles et y laisse son empreinte. " (p. 4). De Québec il disait: “ Ce cap à la mine hardie et hautaine; cette fière citadelle avec son air de touch me not, comme dit l'anglais, qui s'étend en fierté; ces murailles avec leur ceinture de canons et leurs fossés du moyen âge; ce vaste bassin d'un port rival de celui de Naples; ce paysage grandiose et sévère; l'ampleur de cet horizon borné au loin par le cap Tourmente; et que d'autres beautés qu'il serait trop long d'énumérer ! voilà une faible idée de la vieille Capitale de la Nouvelle-France, sur laquelle a flotté glorieusement le 
drapeau fleurdelisé de Saint Louis. Là, cependant, se rencontre le type de la domination, de la supériorité arrogante, de l'autocratie impérieuse et arbitraire, d'un froid dédain mal déguisé pour toute autre grandeur que la sienne, d'une crainte malsaine de descendre de cette hauteur... la fière Métropole entend bien que personne ne soit assez osé pour douter d'elle, qu'on ne cesse de l'admirer avec tous ses beaux atours anciens et nouveaux; qu'on s'incline humblement devant elle; même devant ses parvenus incapables de soutenir son antique gloire; qu'on s'honore d'être admonesté par elle, instruit par elle, gouverné par elle, jugé par elle; bref, que ne veut-elle pas, que n'exiget-elle pas comme étant son droit inaliénable? Aussi, comme cette couleur locale est profondément empreinte sur la lettre Québécoise !» (pp. 8-9).

Lui qui avait accusé d'insolence le rédacteur du Canadien critiquant son sermon des noces d'or, il se croyait à l'abri de tout reproche: "Quant à critiquer des lettres lançées dans le public pour le tromper, c'est le droit et le devoir de quiconque peut tenir une plume, qu'il soit abbé ou non, grand ou petit, de critiquer ces lettres, pourvu que sa critique soit juste et vraie ") (p. 24).

Sur les entrefaites, on annonça le départ prochain de Mgr Taschereau pour Rome, où il devait porter la cause de l'Université Laval et celle des Sulpiciens contre l'évêque de Montréal. Le NouveauMonde publia alors (3 déc.) un article méchant de M. Pelletier intitulé Une page d'histoire! St. Sulpice et le Séminaire de Québec et signé Justitia; ce qui lui attira un charitable avertissement de la part de Mgr Bourget (7 déc.): " Je vous recommande instamment de ne rien souffrir, dans les polémiques que vous avez à soutenir, qui puisse tant soit peu être contre le respect dû à Mgr l'archevêque de Québec et aux évêques de la Province et autres. Je saurai toujours, quand il faudra, me justifier autrement. ")

Dans un discours sur l'Action de Marie dans la société, prononcé à Montréal en la fête de l'Immaculée Conception (1872), le G.-V. Raymond, supérieur du Séminaire de Saint-Hyacinthe, avait affirmé qu'au Canada il n'y avait pas de libéralisme dans le sens condamné par le Vicaire du Christ, pas de gallicanisme non plus. C'était plus qu'il n'en fallait pour faire bondir les rédacteurs du Franc-Parleur. Alphonse Villeneuve, auteur de la Comédie infernale ou conjuration libérale aux enfers, signa du pseudonyme de Binan une série d'articles où il prenait 
à parti le G.-V. Raymond: Le Grand-Vicaire Raymond et le libéralisme catholique. En même temps, M. Pelletier en publia, sous son pseudonyme de Luigi, une autre série: Il y a du libéralisme et du gallicanisme en Canada ${ }^{34}$. Il protestait contre cet excès de zèle pour l'honneur de notre nom, contre ce certificat d'orthodoxie générale, et s'en prenait pour sa part à un personnage québécois. "Il n'est pas un chef de parti, à proprement parler, car il n'a ni les talents brillants, ni les lumières, ni les autres qualités qui conviennent à celui qui joue semblable rôle; mais, à cause de sa médiocrité même, il est devenu, un concours de circonstances assez singulières l'ayant élevé à une haute position, un instrument docile et précieux dans les mains de ceux qui ne se sont pas fait scrupule de l'exploiter en le flattant. Désireux d'exercer une grande influence, il est au service des idées et des mesquines passions d'une foule d'intrigants, de libéraux et de gallicans, qu'il s'imagine cependant diriger. Il les sert ainsi doublement: c'est un masque et un instrument. Du reste, c'est un excellent homme, chez qui l'on trouve un cœur d'or et de hautes vertus. Il s'appelle M. le G.-V. Cazeau » (pp. 5-6).

Et il le montrait à l'œuvre contre le Courrier du Canada, contre la Gazette des Campagnes - " Il faut plaindre ce pauvre M. Cazeau qui fait fi de la doctrine pour respecter des étrennes ") (p. 12)-, dans la persécution dirigée contre l'abbé Jos.-S. Martel, qui réclamait une réforme de la loi d'éducation, contre le G.-V. Louis Proulx et contre le P. Braun, relégués, le premier dans la " colonie pénale » de la Beauce, le second à Montréal, le " refuge des pécheurs ", enfin dans l'affaire des registres paroissiaux, qu'on voulait séculariser.

Quant au gallicanisme, qui accorde à la puissance civile le droit de s'ingérer dans les affaires ecclésiastiques, il en déplorait l'existence chez nous: témoin l'enseignement du droit civil, basé sur Pothier, le Code des Curés du juge J.-H. Baudry, l'affaire Guibord, et la tempête soulevée par le sermon du P. Braun ${ }^{35}$.

34. Les deux séries furent réunies en brochures.

35. Comme il s'était attiré des reproches de la part de Mgr Bourget (lettre du 4 janvier 1873), et qu'un article du Nouveau-Monde (du 8 janvier 1873) avait mis en vedette douze propositions douteuses extraites de son discours, Mgr Raymond jugea bon de faire examiner ce dernier par Rome. Le 3 avril 1873, la Congrégation de la Propagande fit connaître à l'archevêque de Québec que le Saint-Office « a jugé qu'il ne se trouve rien qui mérite censure dans le discours Action de Marie dans la Societé. " Cf. C.-P. Chnquette. Histoire du Seminaire de Saint-Hyacinthe, I, 443-447. 
Cette brochure de Luigi fut suivie de deux autres, assez considérables, du même auteur. Ce ut d'abord Du Modérantisme ou de la fausse modération ${ }^{36}$, un plaidoyer pro domo, pour justifier son intransigeance, et même ses violences, dans sa polémique contre les libéraux catholiques. Puis ce fut Le Don Quichotte montréalais sur sa rossinante ou M. Dessaulles et la Grande Guerre Ecclésiastique ${ }^{37}$, où il donnait de graves leçons de théologie au pontife de l'Institut Canadien, mais d'où la raillerie n'était pas absente. Qu'on en juge par ces extraits. "M. Dessaulles doit se sentir soulagé. Le pauvre homme souffrait d'une furieuse indigestion, si l'on en juge par la masse informe et putride qu'il a vomie (p. 1). Entre tous les évêques, il en est un qui a le privilège de lui déplaire singulièrement, et c'est surtout pour harceler cet évêque qu'il a mis au jour le monstrueux pamphlet hérétique qu'il intitule: La Grande Guerre Ecclésiastique. Cet évêque est Mgr de Montréal. Il se plaint que le vénérable prélat est toujours sur son dos. C'est peu croyable, car jamais Mgr de Montréal ne s'est servi d'une aussi chétive monture, quelque amour de l'humilité qu'il ait (pp. 3-4). Vous profitez, M. Dessaulles, des discussions et des divergences d'opinions dont je viens de parler, pour adresser un très pauvre compliment à Mgr l'archevêque de Québec, de même qu'aux évêques de Saint-Hyacinthe et de Rimouski. Vous les félicitez, en effet, de favoriser des opinions qui finiront, espérez-vous, par étouffer l'ultramontanisme en Canada... Je ne ferai pas à Mgr l'archevêque de Québec, non plus qu'à NN. SS. les évêques de Saint-Hyacinthe et de Rimouski, l'injure de croire que vous les avez bien jugés. Non, certes; ces vénérables prélats veulent être franchement ultramontains, et ils l'ont déclaré en de solennelles circonstances. Vous n'avez donc pas raison de les prendre sous votre égide et de les réclamer comme vôtres, quoi que puissent donner à croire certains de leurs actes qu'ont applaudis les coryphées de l'impiété et du rougisme en Canada. Mais je ne puis m'empêcher d'avouer qu'ils subissent aujcurd'hui devant tout le pays la plus terrible de toutes les épreuves, en recevant vos approbations, vos applaudissements et vos hommages. Cette épreuve si profondément humiliante, Dieu la permet sans doute pour épurer

36. Parue en articles dans le Franc-Parleur, du 29 mars au 20 juin 1873.

37. Le début en fut publié dans le Franc-Parleur du 23 juillet 1873. 
leur vertu et leur faire aimer davantage ces doctrines qu'on désirerait leur voir répudier »(pp. 77-79). Luigi continua, dans des articles du Franc-Parleur ${ }^{38}$, de malmener Dessaulles, en particulier pour son Examen de la soi-disant réfutation de la Grande Guerre Ecclésiastique, par un Faillible.

Depuis qu'il était à Montréal, M. Pelletier n'avait guère donné de répit à sa plume. Une telle tension d'esprit avait ébranlé sa santé. A Saint-Fidèle, où il s'était retiré, il reçut une lettre de Mgr Bourget (19 juin 1873) qui lui recommandait « de ne pas vous fatiguer ni en réfutant M. Dessaulles, ni en composant d'autres écrits ), et qui l'invitait à revenir à Montréal prendre du repos, " si vous vous apercevez que votre séjour porte ombrage et compromette vos amis. ") A l'automne de 1873, l'évêque lui offrit la cure de l'île Bizard, et, sur son refus, il lui en accorda une autre, celle de Saint-Bruno de Chambly.

M. Pelletier continua de collaborer régulièrement à la rédaction du Franc-Parleur. La question des classiques lui tenant toujours à cœur, il résuma toutes ses idées sur le sujet dans une série d'articles qui furent réunis en brochure: La Réforme chrétienne des études classiques, par un collaborateur du "Franc-Parleur ". Voici à quelle occasion. Par un bref du 22 avril 1874, Pie IX avait encouragé Mgr Gaume à ne pas se laisser émouvoir par les oppositions et les critiques malveillantes de certains hommes. Dans un article des Études ${ }^{39}$, reproduit au Canada, le P. Brucker, S.J. avait atténué l'importance du document pontifical et s'était permis de tancer les gaumistes canadiens.

Qu'on me permette quelques citations de cette nouvelle brochure de Luigi. "Afin d'obliger les jeunes gens à se mieux couler dans le moule païen, on leur donne à composer tel discours ou telle harangue qu'Alexandre, Philippe, Brutus, Mucius-Scévola, Coriolan, Camille, Ménénius-Agrippa, Cincinnatus, Annibal, Scipion, Fabius, Marius, Catilina, etc., etc., est supposé avoir prononcé dans telle et telle circonstance. "Il faut, leur dit le professeur, que vous vous transformiez en celui que vous avez à faire parler. Oubliez-vous pour n'être que lui; placez-vous à son point de vue; prenez ses idées, ses sentiments, pénétrez-vous-en et puis çà ira!!! Nous allons voir si vou.s avez

38. 19 septembre, 3 et 10 octobre 1873 .

39. Le Bref à Mgr Gaume, dans Etudes, XXX (1874¹) 905. 
profité de l'étude de vos auteurs et si vous possédez bien votre histoire ancienne. A genoux maintenant! Veni, Sancte Spiritus, reple tuorum corda fidelium, etc. " Je demande ce que le Saint-Esprit a à voir là-dedans. On l'invoque tout de même, et ces pauvres écoliers se mettent à l'œuvre! Ils suent sang et eau et se torturent sans merci afin de parvenir à penser, à sentir et à parler comme de véritables païens. A force de répéter cet exercice, ils se faussent le jugement; et c'est alors qu'on les proclame très versés dans la connaissance de la belle antiquité. Nous former comme si nous devions un jour émigrer dans la lune ne serait pas plus ridicule" (p. 59).

Et, à propos du beau latin: « En France, dans une maison de haut enseignement, un professeur de renom consacrait quatorze leçons à révéler toutes les beautés de ce seul vers d'Horace: Ibam forte via sacra. Imaginez donc! Dans quelques centaines d'années d'ici, lorsque le français sera devenu langue morte, il se trouvera que, nous aussi, nous aurons dit des choses merveilleuses sans nous en apercevoir. Tous ceux, même les charretiers assez peu cultivés, qui auront eu la bonne fortune de laisser échapper cette phrase: « Je me promenais par hasard dans la rue Ste Catherine "), seront placés à côté de l'immortel Horace, dans le temple de la Gloire " (p. 68).

Passant de la raillerie à la prophétie, il lançait ce suprême argument en faveur de la réforme: "Tôt ou tard l'éducation dans notre pays passera des mains du clergé dans celles des laïques, si on continue à la donner d'après le système païen. L'illusion n'est guère possible: ce qui a eu lieu en France depuis 89 aura lieu ici pour les mêmes raisons. Tout nous donne à penser et à croire que non seulement la chose est possible, mais qu'elle se réalisera dans un avenir assez prochain. Et, en effet, on ne tardera à dire tout haut que pour enseigner du latin et du grec purement et simplement, pour commenter et faire goûter les classiques anciens, les laïques sont aussi habiles que les ecclésiastiques; qu'il n'est pas besoin de porter la soutane pour faire des cours de littérature profane. Qu'aura-t-on à répondre à un pareil argument, si la méthode d'enseignement reste ce qu'elle est? Rien, absolument. Si donc le clergé veut rester maître de l'éducation, qu'il la donne chrétienne comme lui seul peut et doit la donner. On n'aura plus de raisons à faire valoir contre lui » (p. 183).

M. Pelletier revint aussi sur la question du libéralisme, dans deux brochures qui reproduisaient ses articles du Franc-Parleur. La pre- 
mière avait pour titre: M. l'Abbé Sax et ses souffleurs ou Réfutation des Erreurs contenues dans le Manifeste Libéral Québecqwois, par un conservateur catholique, et se terminait par cette litanie: A PESTE LIBERALI, LIBERA, DOMINE !!! Quelques jours avant les élections provinciales du 7 juillet 1875, les journaux libéraux avaient publié une lettre d'Un Prêtre, vite identifié avec l'abbé Pierre Sax, curé de Saint-Romuald, qui, sous prétexte de tranquilliser la conscience d'un citoyen (son ami Joseph Cauchon, au dire de M. Pelletier), affirmait que les deux partis en présence avaient d'égales sympathies dans les rangs du clergé de chaque comté et n'avaient d'autre programme que celui de l'Eglise romaine. M. Pelletier démasquait le jeu de l'abbé Sax et de ceux qui se cachaient derrière lui: ils voulaient par là rallier un certain nombre d'indécis en faveur du candidat libéral du comté de Lévis, le neveu Etienne-Théodore Pâquet. " Non, disaitil, les libéraux ne sauraient s'appuyer sur une fraction quelque peu notable de notre clergé qui les repousse et les abhorre. Quelques rares individus seulement se sont détachés de ses rangs pour faire cause commune avec eux. Hls sont en si petit nombre qu'on ne les compte pas même par douzaines. Dans toute la province de Québec, c'est tout au plus s'il y en a vingt, y compris M. Sax et ses souffleurs (p. 16). Notre parti libéral canadien a des doctrines avouées et bien connues, et ces doctrines sont tout à fait identiques à celles que professent les libéraux des autres pays (p. 17)... et ceux qui de bonne foi sont demeurés jusqu'ici dans les rangs de ce parti, doivent rompre entièrement avec lui, s'ils veulent être en sûreté de conscience ") (p. 40).

Ce sont ces mêmes idées qu'il développa dans la seconde brochure: Coup d'œil sur le libéralisme européen et sur le libéralisme canadien. Démbnstration de leur Parfaite Identité, soutenant "que les idées catholiques libérales européennes sont depuis longtemps prêchées au Canada, sur tous les tons et sous toutes les formes, depuis la thèse de théologie jusqu'à l'article de journal » (p. 65).

Le dimanche 23 juillet 1876, invité à prêcher par le curé de la Malbaie, un ami chez qui il prenait quelques jours de repos, il fit un sermon sur les rapports de l'Église et de l'Etat dans le sens de la bulle Unam Sanctam, démontrant que, toutes les fois qu'il s'agit du bien spirituel des âmes, l'Église a le droit de faire des lois qui obligent strictement, même les gouvernements. C'était l'epoque où s'instruisait le procès en invalidation de l'élection du comté de Charlevoix 
pour raison d'influence spirituelle indue. Des libéraux qui étaient présents au sermon s'en montrèrent scandalisés, et l'un d'eux, Pitre Tremblay, fit des démarches pour le faire condamner. Les journaux libéraux s'acharnèrent contre l'audacieux prédicateur. L'Événement le dénonça comme étant le George St. Aimé jadis censuré par Mgr Baillargeon. C'est alors que, pour se mieux défendre, M. Pelletier donna ses preuves de l'existence du monitum adressé par le Saint-Office au défunt archevêque de Québec au sujet de son mandement du mois d'août 1868. Israël Tarte crut servir l'intérêt de la justice et de la vérité en reproduisant dans son journal, le Canadien de Québec, les articles publiés par Luigi dans le Franc-Parleur. Mgr Taschereau intervint aussitôt pour avertir Tarte que le mandement du 12 août 1868, défendant de ne rien publier sur la question des classiques sans la permission de l'Ordinaire, était encore en pleine vigueur. Il s'ensuivit un échange de lettres aigres-douces entre le rédacteur du $\mathrm{Ca}$ nadien et l'archevêque de Québec. A la fin, Mgr Taschereau retira son abonnement et menaça d'interdire la lecture du journal. Tarte écrivit au cardinal Franchi à Rome, pour se plaindre de l'archevêque et pour demander justice et protection ${ }^{40}$.

De son côté, M. Pelletier avait décidé d'écrire au cardinal Patrizi pour savoir ce que la Congrégation de l'Inquisition (Saint-Office) avait décrété relativement aux brochures de George St. Aimé et aux peines ecclésiastiques portées contre lui. Il lui avouait qu'il était George St. Aimé et qu'il n'avait pas tenu compte de ces peines. Comme cette affaire s'était passée dans le diocèse de Québec, le cardinal ècrivit de suite à Mgr Taschereau pour avoir des renseignements. On devine le portrait peu flatteur que ce dernier dut faire de M. Pelletier.En conséquence des informations reçues, le cardinal Caterini écrivit, le 25 novembre 1876, à l'évêque de Montréal, que le prêtre Alexis Pelletier, qui exerçait le ministère dans son diocèse, avait été légitimement censuré par l'archevêque de Québec, qu'il s'était rendu très coupable en ne respectant pas la censure, qu'il avait encouru l'irrégularité et qu'il ne pouvait être absous qu'en reconnaissant humblement tous ses torts et en renonçant pour toujours à écrire sur la question des

40. La lettre au cardinal Franchi, comportant aussi la correspondance TarteTaschereau, se trouve dans les brochures Autour d'une carrière politique Joseph Israël Tarte, 1880-1897, [1897]. pp. 38-58, et Judas Iscariote Tarte, [1903], pp. 50-73. 
classiques. Mgr Taschereau eut vent de cette décision, par une lettre du cardinal Guidi, et il écrivit à Mgr Fabre (9 janv. 1877) pour exiger que M. Pelletier rendit sa condamnation publique. Pour avoir la paix, M. Pelletier fit paraître dans le Franc-Parleur du 19 janvier 1877, le communiqué suivant que les journaux reproduisirent:

\section{Un avertissement du Saint-Office à George St. Aimé}

( Par une lettre en date du 25 novembre dernier, la Congrégation du St. Office, par son Eminentissime secrétaire, le cardinal Caterini, a chargé Mgr de Montréal de me signifier que, dans deux brochures signées par moi du pseudonyme de George St. Aimé, "j'ai attaqué d'une manière violente et irrévérentieuse tant les déclarations du St. Siège que les actes de l'autorité diocésaine... duorum librorum larvatum nomen George St. Aimé proeferentium, qu々bus tum declarationes S. Sedis tum acta auctoritatis dioecesanae acriter et irreverenter impetebat (auctor): qu'en conséquence toutes les peines portées contre moi et contre ces deux brochures par Mgr Baillargeon, ont été tout à fait justes et méritées; que j'ai encouru les censures et l'irrégularité; qu'il m'est strictement interdit d'écrire davantage, soit des brochures, soit des articles de journaux sur la question des classiques, que je signe de mon vrai nom ou d'un pseudonyme; que si j'accepte enfin ces avertissements et ces prescriptions, promettant sérieusement de m'amender, Sa Grandeur Mgr de Montréal pourra me relever, de par autorité pontificale, de toutes les peines encourues." Comme ces deux brochures ont fait grand bruit, je crois devoir, puisque Rome les juge fort condamnables dans leur forme, rendre la condamnation qui me frappe aussi publique que possible ").

" Malgré la lettre que Son Eminence le cardinal Patrizi écrivait à Mgr Baillargeon, au nom du St-Office et à la date du 15 février 1867, je crus qu'il n'était aucunement défendu d'insister souvent sur ce qu'avait réglé le St. Siège relativement aux études, pour qu'on le mît partout parfaitement en pratique; qu'il m'était toujours permis d'écrire au Canada comme le font encore actuellement en Europe Mgr Gaume, Mgr l'archevêque d'Aquila, Son Eminence le cardinal d'Avanzo, évêque de Clavi et Teano, ainsi que beaucoup d'autres, d'autant plus que d'illustres personnages m'exhortaient à le faire. Je crus encore que, eu égard aux actes de l'autorité diocésaine, je me 
tenais dans les limites tracées par d'eminents prélats, entr'autres par Mgr de Dreux-Brézé et Mgr Parisis, vu surtout que je m'efforçais de prendre pour modèles les répliques faites publiquement à de vénérables évêques par Mgr Gaume et Dom Guéranger abbé de Solesmes.»

"Quant aux peines portées contre moi et contre mes brochures, je les ai jugées nulles et de nul effet, m'appuyant tant sur la théologie que sur plusieurs très graves autorités du pays et de l'étranger. Je savais cependant que je devais respecter extérieurement les prescriptions de la circulaire de Mgr B'aillargeon dans tout ce que ces prescriptions contenaient qui n'était point de nature à me faire connaître comme étant George St. Aimé. Aussi, voilà pourquoi je n'ai jamais plus rien écrit sur la question des classiques, tant que je suis demeuré dans le diocèse de Québec. »

" Maintenant, le St. Office déclare que je me suis trompé, que j'ai mal agi et me défend d'écrire davantage. Je n'ai point à raisonner, à hésiter, encore moins à diccuter et à chercher des échappatoires. Mon devoir est d'accepter la leçon qui m'est donnée, de me soumettre, et je me soumets de grand cœur. J'ai voulu, comme je voudrai toujours, une obéissance pleine et entière, non seulement aux paroles du pape, mais aux décisions des saintes Congrégations romaines; je suis heureux d'avoir à pratiquer publiquement ce que j'ai constamment enseigné dans mes écrits. N'ayant voulu servir que la sainte cause du bien, je cesse d'agir quand la voix si sage et si autorisée de Rome prononce que mes travaux sont mauvais et partant nuisibles. J'ai voulu obéir au St-Siège en écrivant, je lui obéirai encore en m'abstenant d'écrire. Je cesse d'écrire non seulement sur la question des classiques, qu'il ne m'est plus permis de traiter, mais sur toute autre question, parce que désormais mes écrits n'obtiendraient aucun bon résultat ${ }^{4}{ }^{1}$. Je bénis Dieu de l'humiliation qui pèse sur moi, et je suis convaincu que cette humiliation servira mieux sa cause que les plus beaux écrits que je pourrais faire. Bonum mihi quia humiliasti me. »"

41. Une fois tout au plus, M. Pelletier dut-il être rappelé au respect de ses engagements par une lettre de Mgr Fabre (25 juillet 1881): il avait engagé, dans la Minerve (12 et 18 juil. 1881), une polémique contre un Clericus, qui l'avait mis en cause pour avoir signé et fait signer par ses paroissiens de Valleyfield une requête contre le bill de la succursale de Laval à Montréal. Une autre lettre de Mgr Fabre (11 juin 1887) contient une allusion, sans reproche, à un article que $M$. Pelletier avait publié dans l'Etendard (9 mai 1887) pour protester contre l'affirmation d'Un curé voulant que tout ce qu'avait écrit Luigi avait été condamné. (Note de l'auteur) 
( Il ne me reste plus qu'à demander très humblement excuse à toutes les autorités diocésaines que j'ai pu offenser dans mes écrits. Je demande tout particulièrement mille excuses à Mgr l'archevêque de Québec pour tout ce dont j'ai pu me rendrec oupable à son égard.»

( En terminant, je prierai tous ceux que j'ai combattus de croire que je ne sais ni haïr, ni avoir de rancune. Je n'en ai jamais voulu à qui que ce soit et ma plume n'a jamais servi la passion. Je n'ai haï et je ne hais que l'erreur et le mal. Je prie les journaux canadiensfrançais de vouloir bien reproduire cet écrit. ") (signé) Luigi alias Alexis Pelletier, Ptre.

Après une telle humiliation, on aurait pu croire qu'il ne relèverait jamais la tête. Il n'en fut rien. Mgr Filippi et Mgr Gaume, qui connaissaient toutes les brochures signées George St. Aimé, et qui les avaient même en leur possession, écrivirent à M. Pelletier, après qu'ils eurent appris la nouvelle de sa condamnation, pour le féliciter d'avoir accepté cette condamnation, "quoique mal fondée et extorquée par de honteux mensonges "). Encouragé par ces lettres, il adressa au cardinal Caterini, en même temps que les trois brochures de George St. Aimé et le numéro du Franc-Parleur contenant sa rétractation, un mémoire imprimé - en beau latin-, pour corriger des informations fausses fournies par ses adversaires et pour demander que la sentence portée contre lui et ses écrits fût réformée. N'ayant rien obtenu, il prépara sa revanche contre Mgr Taschereau. C'est la brochure intitulée La Source du Mal de l'Époque au Canada, par un catholique, et qui peut se résumer en cette phrase: « S. E. le cardinal Siméoni dit que la cause des maux qui règnent parmi nous, c'est la division des évêques. Oui, tel est le cas. Mais quelle est la cause de la division de nos évêques entre eux, si ce n'est, comme le démontre péremptoirement cet exposé des faits, si ce n'est le seul archevêque Taschereau? C'est bien ici le temps de rappeler ce qu'on disait de lui, avant qu'il fût promu à l'épiscopat: " Si cet homme devient archevêque de Québec, ce sera la plus terrible épreuve que l'église du Canada ait jamais subie ») (p. 111).

Arthur Savaëte, qui le reproduit en l'annotant dans le tome III de ses Voix Canadiennes: Vers l'abîme, nous apprend (p. 30) que ce Mémoire avait d'abord été présenté par son auteur lui-même, mais en manuscrit, à Mgr George Conroy, évêque d'Ardagh en Irlande, venu 
au Canada en qualité de Délégué apostolique, en 1877. Revisé et sensiblement augmenté, il avait été soumis à Mgr Bourget et $\mathrm{Mgr}$ Pinsonnault, puis imprimé, vers la fn de 1881, par les soins et aux frais du recorder Benjamin-Antoine Testard de Montigny, pour être remis à Mgr Laflèche, qui se rendait alors à Rome. L'auteur n'avait permis d'en tirer qu'un très petit nombre d'exemplaires, hors commerce, et à la condition expresse qu'il resterait un Mémoire confidentiel réservé comme il était, et exclusivement destiné aux autorités majeures dans l'Église, telles que les Congrégations romaines, le Saint-Siège et ses représentants qualifiés et spéciaux.

$A u$ bout de deux ans, la brochure finit par tomber entre les mains d'indiscrets. Un rédacteur de la Patrie (Louis Fréchette) la dénonça dans un article du 11 janvier 1884: " J'ai acheté hier, où ça se vend au prix de 50 cents, chez MM. Cadieux et Derome, libraires, un pamphlet intitulé: La Source du Mal de l'Époque au Canada, par un catholique. Cela ne porte ni nom d'auteur, ni nom d'éditeur, ni date, ni aucun signe enfin qui puisse en faire connaître la provenance. Une saleté anonyme, qui a vu le jour on ne sait ni pourquoi ni comment; et comme c'est une affaire religieuse, la recherche de la paternité est interdite. C'est un engueulement en règle contre $\mathrm{Mgr}$ l'archevêque de Québec, contre feu Mgr Conroy et contre tous les ecclésiastiques qui, de près ou de loin, sympathisent avec la cause de l'Université Laval. C'est un bouquin préconisé par le grand vicaire Trudel, approuvé par papa Vincelette de l'asile de Beauport, et inventé dans le silence du cabinet par un petit vicaire quelconque, aidé des conseils de quelque gros curé de la tribu des Castors... Cela commence par dire que ( les catholiques du Canada sont dans un état de grande souffrance et que les messieurs du Séminaire de Québec conspirent entre eux pour tromper le Saint-Siège et lui faire envisager sous un faux jour l'état de choses qui règne au Canada. " Vous voyez que cela débute comme un ancien mandement de Mgr Bourget à l'adresse des libéraux.. ")

Dans une circulaire à son clergé, du 20 janvier (1884), Mgr Fabre flétrit la brochure en termes très sévères, obligeant à la brûler, sous peine de cas réservé à l'évêque ou à son grand vicaire pour les laïques, et même dans les vingt-quatre heures sous peine de suspense $i p s o$ facto pour les membres du clergé ${ }^{42}$. Mgr Taschereau fit de même, dans une

42. Mandements des evêques de Montréal, IX, 539-541. 
circulaire du 2 février suivant, mais avec la morgue qu'on lui connaissait: " Si j'étais seul attaqué dans ces pages où la vérité est outragée, jen'en aurais pas fait plus de cas quebien d'au tres écrits du même genre. Mais l'auteur, qui se cache lâchement sous l'anonyme et qui ose se dire catholique, une fois sorti de la voie droite, ne respecte rien: des prêtres vénérables que la tombe aurait dû protéger contre l'insulte ${ }^{43}$, les institutions les plus méritantes, les évêques, mes prédécesseurs, et quelques-uns de mes suffragants, les congrégations romaines, les représentants du Saint-Siège, tout est couvert de boue, accusé de toutes manières. S'il n'a pas osé attaquer directement et personnellement le Souverain Pontife, c'est moins par respect pour cette suprême autorité que par crainte de se compromettre lui-même d'une manière trop évidente. " ${ }^{4} 4$ Des autres évêques, Mgr Antoine Racine, de Sherbrooke, fut seul à condamner la brochure.

L'auteur échappa à toute censure de la part de son évêque, Mgr Fabre. Il lui avait pourtant écrit, le 1er février: " Permettez-moi maintenant, Monse:gneur, de vous dire que je sais que vous me connaissiez comme l'auteur de la brochure que vous avez condamnée, au moins quatre jours avant le jour dont votre circulaire porte la date. Je le sais par plus d'un, et entr'autres par Mr Desmarais, notre vicaire forain, à qui vous avez dit que j'étais cet auteur, mercredi le 16 janvier dernier. Et puisqu'il est question de M. Desmarais, je vous dirai qu'il a tant trouvé d'extraordinaire dans l'affaire qu'on me suscite à l'heure présente, qu'il m'a conseillé, samedi dernier le 26 , de défendre mes droits et jusqu'au bout. »

Il échappa même à toute censure de la part du Saint-Siège, mais quelle épreuve pour sa foi, lorsqu'il apprit, deux ans plus tard, que Rome accordait le chapeau cardinalice à celui qu'il lui avait si âprement dénoncé ! Cette fois, il était définitivement vaincu. En 1891, il démissionna de la cure de Valleyfield, où il avait été transféré en 1878 , et se retira à S'aint-Gabriel de la Pointe Saint-Charles, où il

43. L'auteur allait jusqu'à piétiner le cadavre de son ancien adversaire, l'abbé Chandonnet, "qui vient de mourir misérablement, après avoir passé plusieurs années dans une profonde dégradation... ". La Source du Mal de l'Epoque, 31. L'abbé Chandonnet était mort d'apoplexie foudroyante, le 4 juin 1881. On l'avait trouvé étendu sur son lit, dans une chambre attenante au bureau de la Revue de Montréal. (Note de l'auteur)

44 Mandements des evếques de Québec, nouvelle série, II, 391-391. 
remplit les fonctions de pro-vicaire. En 1895, il devenait aumônier du Bon-Pasteur de la rue Sherbrooke, à Montréal.

Pendant quinze ans, il édifia les religieuses et les pensionnaires de cette institution par sa piété autant que par sa doctrine. Levé très à bonne heure, il faisait le Chemin de la Croix tous les jours. En dépit de sa grande facilité de parole, il soignait la préparation de ses instructions et de ses catéchismes. Les confrères plus jeunes mettaient sa science à contribution pour préparer leurs rapports aux conférences ecclésiastiques. Lorsque d'aventure la conversation aiguillait sur les difficultés religieuses d'autrefois, on voyait passer des éclairs dans ses yeux. "La faute en est à Mgr Persico ", échappait-il devant ses auditeurs ${ }^{45}$.

Il décéda au presbytère du Bon-Pasteur, dans la soirée du 25 juin 1910, d'un cancer à la gorge qui l'avait fait souffrir pendant plusieurs mois. Mgr Racicot chanta le service et Mgr Bruchési prononça un éloge funèbre, qui se terminait sur ces mots: " Demandons à Dieu de nous donner beaucoup de prêtres aussi instruits, aussi pieux et aussi bons que M. Pelletier $"{ }^{46}$.

Faut-il conclure: Tout est bien qui finit bien? Je ne le pense pas. Certes, M. Pelletier défendait de bonnes cause:. Comment lui refuser raison d'avoir fait ressortir l'illogisme d'une éducation chrétienne qui se donnail presque exclusivement au moyen d'auteurs païens, d'avoir mis en garde contre l'équivoque qui faisait le jeu des esprits libéraux les plus avancés? Mais n'exagérait-il pas la novicité des études classiques telles qu'elles se pratiquaient alors au pays? Faisant allusion à la polémique de M. Pelletier, Joseph-Edmond Roy écrit, dans ses Souvenirs d'une classe au Séminaire de Québec (p. 435): "Nous étions alors (1869) en sixième, et nous commencions justement à apprendre la mythologie. Les dieux de l'Olympe continuèrent donc à régner en maîtres sur nos études, et nous n'avons pas été plus païens pour tout cela. ") Ce qui est certain, c'est qu'il a usé de procédés trop violents vis-à-vis de ses adversaires, et trop irrespectueux vis-à-vis de l'autorité, ce qui ne pouvait que le discréditer aux yeux du Saint-Siège,

45. Mgr Persico, italien, ancien évêque de Savannah (Géorgie), curé de SaintColomban de Sillery (1873-1876) était un envoyé secret de la Propagande au Canada, chargé d'étudier sur place la situation religieuse du pays.

46. Semaine religieuse de Montréal, 18 juillet 1910, vol. LVI, 41. 
auquel il prétendait obéir en combattant de la sorte. On ne vilipende pas impunément l'autorité. A défaut de l'humilité évangélique, un examen plus attentif eât appris à ce contempteur de l'antiquité païenne la petite leçon de sagesse que voici: "Adrien l'empereur débattant avec le philosophe Favorinus de l'interprétation de quelque mot, Favorinus lui en quitta bientôt la victoire. Ses amis se plaignant à lui: "Vous vous moquez, fit-il, voudriez-vous qu'il ne fût plus savant que moi, lui qui commande à trente légions? " - Auguste écrivit des vers contre Asinius Pollion. "Et moi, dit Pollion, je me tais; ce n'est pas sagesse d'écrire à l'envie de celui qui peut proscrire.) ${ }^{4} 7$

Des luttes comme celles qu'il a menées ne sont jamais stériles. Quant à moi, tout en reconnaissant leurs torts, je réserve une part de mon admiration à ceux qui y risquent leur peau, car l'histoire m'a appris que bien souvent les succès de la modération sont conditionnés par les excès mêmes de ces intrépides aboyeurs.

Thomas Charland, O.P.

Professeur de palégraphie et de bibliographie a l'École des bibliothécaires de l'Université de Montréal.

47. Henri Bremond, Adieux à la controverse, dans la Vie spirituelle, supplément XXIII, [27-28.] 